\title{
LA TIERRA EN RAPA NUI. LA POLIITICA DEL PARENTESCO Y LOS DISPOSITIVOS ESTATALES. CONSENSOS Y DISENSOS EN LA DEFINICIÓN DE LA PROPIEDAD
}

\author{
The Land in Rapa Nui
}

The Policy of the Kinship and the State Devices.

\section{Consensus and Dissent in the Property's definition}

\section{DIEGO MUÑOZ*}

Fecha de recepción: 14 de abril de 2020 - Fecha de aprobación: 07 de noviembre de 2020

\section{Resumen}

Uno de los asuntos centrales en las relaciones entre la sociedad rapanui y el Estado chileno concierne a la propiedad de la tierra y las formas de su transmisión. Se analiza aquí la configuración histórica de la propiedad en Hanga Roa, tanto desde el punto de vista rapanui como estatal, y los mecanismos mediante los cuales esta ha sido transmitida en el seno de la comunidad rapanui. Hemos buscado en un corpus de 2.000 documentos oficiales de inscripción de derechos de tierras las cadenas de parentesco que unen a las personas involucradas en las transferencias de derechos. Este análisis abarca noventa años de aplicación de los instrumentos estatales y nos permite identificar las lógicas de acción rapanui en la adquisición y transmisión de la propiedad. Concluimos que la política rapanui de la tierra es una mezcla de criterios locales y estatales, donde el parentesco sigue siendo determinante en la definición de la propiedad y la transmisión de la tierra.

Palabras clave: Rapa Nui; Chile; propiedad de la tierra; parentesco; instrumentos estatales.

\section{Abstract}

One central issue of the relationship between Rapanui society and the Chilean state concerns the policy of land ownership and the ways in which it is transmitted. In this paper, we analyze, on the one hand, the historic configuration of land ownership in Hanga Roa, both from the Rapanui and the state's point of view. On the other hand, we analyze the mechanisms through which the land has been inherited within the Rapanui community. In a corpus of 2000 official documents relating to the inscription of land rights, we have searched kinship chains that unite persons involved in the transfers of rights. This analysis covers 90 years of the application of state instruments and allows us to identify the Rapanui logic of land acquisition and land property transmission. We conclude that the Rapanui's land ownership policy is a mixture of state and local criteria, and that kinship remains a determining factor in defining the ownership and transfer of land.

Keywords: Rapa Nui; Chile; land ownership; kinship; state instruments. 


\section{Introducción}

En este artículo interrogamos el sistema de tenencia de la tierra en Rapa Nui centrándonos en los mecanismos de creación del dominio, la propiedad y la transmisión de esta. Una característica fundamental es que la propiedad rapanui efectiva ha sido ejercida durante los últimos 130 años en el área de Hanga Roa, el único pueblo de la isla. El resto del territorio dejó de estar bajo control rapanui durante la evangelización y el traslado de la población a este sector. El arraigo rapanui en Hanga Roa se vio profundizado luego de la anexión chilena y a través de la aplicación de dispositivos estatales que crearon figuras de tenencia y propiedad. En 1902, con el bando Rojas, se definió un área de 600 hectáreas para la radicación de los isleños y se destinó el resto del territorio a la ganadería (Muñoz, 2017a). La inscripción fiscal del dominio en 1933 y la definición de las tierras fuera de Hanga Roa como Parque Nacional en 1935, redujeron aún más el control rapanui sobre las tierras. Sin embargo, a través de los diferentes dispositivos estatales usados para validar la posesión, el control rapanui sobre ciertos sectores ha ido aumentando paulatinamente (Zurob, 2011; Foerster, Moreno Pakarati \& Ramírez, 2014). Esto último, siguiendo un modelo suis generis que trataremos aquí de dilucidar.

La relación de los rapanui con la tierra ha sido descrita como "especial" y vinculada al parentesco (McCall, 1976; Hotus y el Consejo de Jefes de Rapanui, 1988; Delsing, 2009; Zurob, 2011). Sin embargo, este vínculo no ha sido explicado con precisión. Según Hotus et al. (1988, p. 21):

Para el rapanui, la tierra pascuense tiene un importante significado y un valor diferente al que tiene para otros pueblos y culturas, pero sí similar al de otras culturas polinésicas. Para el pascuense, existe un profundo lazo emocional con esta tierra que los vio nacer y se refleja en el hecho que la tierra se llama "KAINGA". En nuestro idioma que significa a su vez, matriz o útero y los territorios pertenecientes a cada tribu, llamado "HENUA POREKO" o tierra natal, en donde nacieron los ancestros.

La noción de kainga requiere algunas precisiones. Se trata de un término panpolinésico ${ }^{1}$ que, en Rapa Nui, según Englert (1948), evoca al mismo tiempo el acto de comer y los territorio de los antiguos mata (clanes). Kainga cubre así el significado de un espacio de sustento y de la soberanía del clan. Englert (1948) agrega que: "por pequeña que sea la isla, cada [habitante] hablaba de 'su tierra', no en sentido de la isla en general, sino de la zona de su clan" (p. 52). En coherencia con esto, los territorios de cada mata (unos diez, según la etnología clásica) aparecen bien definidos en los mapas de división territorial presentados por los antropólogos de inicios del siglo XX (Routledge, 1919; Métraux, 1971 [1940]) y también, aunque con diferencias importantes, en el mapa propuesto en 1988 por el mismo Consejo de Ancianos Rapanui (Hotus et al., 1988)².

Ahora bien, el vínculo contemporáneo de los rapanui con la tierra no puede ser explicado solamente con la definición tradicional del término kainga indicado por Hotus et al. (1988), sin duda importante, pero no suficiente. Este, desde nuestro punto de vista, se encuentra en la combinación de un proceso histórico de formación de grupos de parentesco, donde los principios de propiedad y de herencia han sido reformulados en diálogo y tensión con los dispositivos estatales que han definido otros principios en esta materia. 
Siguiendo a Firth (1936) y Bambridge (2009), sabemos que, en las sociedades polinésicas antiguas, el derecho de propiedad sobre los kainga se definía a través del criterio de anterioridad en la ocupación y en el de permanencia en el tiempo sobre dichos espacios. Ambos principios aparecen esbozados en la expresión "henua poreko", indicada más arriba. Sin embargo, estos fundamentos se ven afectados en Rapa Nui tanto por el desplazamiento de los diferentes grupos a un solo sector de la isla como por la aplicación de los dispositivos estatales que han tenido por objetivo reglamentar los modos de adquisición y de propiedad. Recordemos que, según el código civil chileno (Art. 582), la propiedad "es el derecho real que una persona tiene sobre un objeto corporal para utilizarlo y disponer de él de forma arbitraria; no siendo contra el derecho o contra la ley ajena la propiedad".

Proponemos que en el caso rapanui operan dos lógicas que se superponen, dialogan y se contrastan: aquellas venidas del sistema de parentesco, donde la ocupación de las tierras durante varias generaciones legitima la propiedad y justifica la herencia; y aquellas definidas por los instrumentos estatales que fundamentan las figuras de propiedad fiscal y de propiedad individual sobre las tierras, donde la noción de arbitrariedad resulta central.

Un aspecto capital en la configuración de la propiedad de la tierra en Rapa Nui es que esta se encuentra o bien en las manos del Estado, luego de la inscripción fiscal de 1933, o bien en las de los rapanui, salvo contadas excepciones $^{3}$. Las tierras fiscales corresponden a $71,48 \%$ de la superficie de la isla ${ }^{4}$, mientras que las rapanui a $22 \%$ de la superficie (MBN,
2011). En este contexto, la lógica rapanui del henua poreko entra en tensión con la aplicación de instrumentos estatales tendientes a crear un domino individual sobre la tierras.

En este escrito nos proponemos analizar cómo los rapanui han creado la posesión sobre las tierras que ocupan en Hanga Roa y mediante qué procedimientos estas han sido transmitidas de una generación a otra. Este análisis concierne entonces solo a $22 \%$ de la superficie de la isla. Nuestra hipótesis propone que luego del desplazamiento y la reducción de los isleños en Hanga Roa, se estructuraron principios de apropiación y de transferencia de derechos que han combinado lógicas de parentesco y procedimientos estatales. Estos principios dan contenido hoy a la relación rapanui con la tierra y permiten entender la esfera conflictual tanto con el Estado como en el seno de la misma comunidad en lo que respecta a la propiedad de estas.

Seguiremos aquí las recomendaciones metodológicas de Balandier (1996) respecto de diferenciar la producción teórica de una sociedad -es decir, los principios ideales que son expresados en discursos- de las acciones concretas de las personas. Asumiendo esto, nos interrogamos sobre los consensos y los disensos respecto de la propiedad de la tierra (Bambridge, 2009). En nuestro caso, el "lazo afectivo profundo" señalado por Hotus et al. (1988) puede ser explicado desde la historicidad de la propiedad y los mecanismos para adquirir y distribuir los derechos sobre las tierras. Un análisis pragmático nos permitirá comprender y describir las lógicas de acción (Bensa, 2006) desplegadas en la reapropiación y la distribución de estas. 
Nuestro análisis consistirá en identificar de qué manera el parentesco fue modificado para permitir la apropiación rapanui de Hanga Roa, proceso iniciado con la reducción misionera en 1868 y perpetuado por la política chilena. Luego, identificaremos los vínculos de parentesco que existen entre los individuos que han entregado tierras (tanto en el sector urbano o rural de Hanga Roa) y aquellos que las han recibido. Determinaremos cuál es la proporción de las relaciones de descendencia, colateralidad y alianza en la distribución de derechos sobre estas una vez que el Estado chileno comenzó a registrar el uso, el goce y la propiedad de las tierras bajo sus propios criterios. Para ello nos serviremos tanto del análisis de un corpus genealógico que hemos organizado, como de los dispositivos estatales destinados a definir el dominio y la tenencia: títulos provisorios, cesiones de derecho y títulos de dominio.

En otro artículo (Muñoz, 2014) describimos las características contemporáneas de los hua'ai, los grupos de descendencia rapanui, indicando las transformaciones internas en la filiación y la mantención de los criterios comportamentales que legitiman la membresía, tales como la participación en los asuntos del hua'ai, ser considerado buen hijo/hija y comportarse con respeto (moa) hacia la autoridad (hatia) de los mayores (matu'a, matu'a rua'u). Nuestro análisis demostró que los hua'ai pasaron de ser exclusivamente agnaticios (Metraux, 1971 [1940]; McCall, 1976) a cognaticios. Pensamos que esta metamorfosis en el parentesco (Godelier, 2009) se debe ver reflejada en los principios de herencia, siendo la tierra uno de los bienes a entregar a la descendencia (McCall, 1976; Zurob, 2011). En otro artículo, hemos señalado también la importancia de las memorias genealógicas (haka'ara) en las definiciones de las identidades indivi- duales y en la conceptualización de la autoctonía (Muñoz, 2017b). Reconociendo el valor memorial y práctico de las genealógicas, estas permiten seguir, lo más cercanamente posible, los vínculos de parentesco por los cuales un determinado título de tierra ha circulado y en el seno de qué grupos de parentesco, segmentos o individuos lo ha hecho.

\section{Corpus genealógico rapanui y su análisis}

Desde 2011 hemos sistematizado un corpus genealógico que abarca hoy un máximo de 14 generaciones compuestas de 4.054 individuos (2.117 hombres y 1.933 mujeres), 1.216 uniones, 896 matrimonios y 6.611 relaciones padreshijos. Este corpus es un trabajo de sistematización y codificación de las listas genealógicas publicadas por el Consejo de Ancianos Rapanui (Hotus et al., 1988, 2007), las genealogías levantadas por Katherine Routledge en $1914^{5}$ y aquellas producidas por Sebastián Englert ${ }^{6}$ y Grant McCall (1986). Hemos sumado a estas listas la información contenida en los censos de 1886, 1916, 1929, 1935 y $1965^{7}$ para estimar fechas de nacimiento, matrimonio y defunción de un importante número de individuos. Finalmente, hemos agregado ciertos detalles proporcionados en los documentos de tierras (títulos provisorios y cesiones de derechos) en los que se individualizan a las personas involucradas en los cambios de propiedad de las tierras.

Para la sistematización y análisis de este corpus genealógico hemos utilizado el programa informático Puck (v. 2.3.65) creado por Klaus Hamberger y el equipo TIP (Traitement informatique de la parenté, EHESS París) (Hamberger, Houseman \& Grange, 2009) ${ }^{8}$. Puck es una potente herramienta que permite identificar 
la totalidad de configuraciones matrimoniales que componen una red de parentesco, sin otra especificación que la talla máxima de las cadenas analizadas (Hamberger et al., 2009). Es decir, con Puck podemos identificar la posición genealógica del antepasado común más cercano, consanguíneo o por alianza entre dos individuos presentes en el corpus (Barry et al., 2000).
Las cadenas de parentesco identificadas con Puck nos han permitido ordenar y cuantificar los tipos de relaciones genealógicas presentes en las transferencias de derechos sobre tierras (Figura 1).

Figura 1. Secuencia de traspaso de un título de tierras

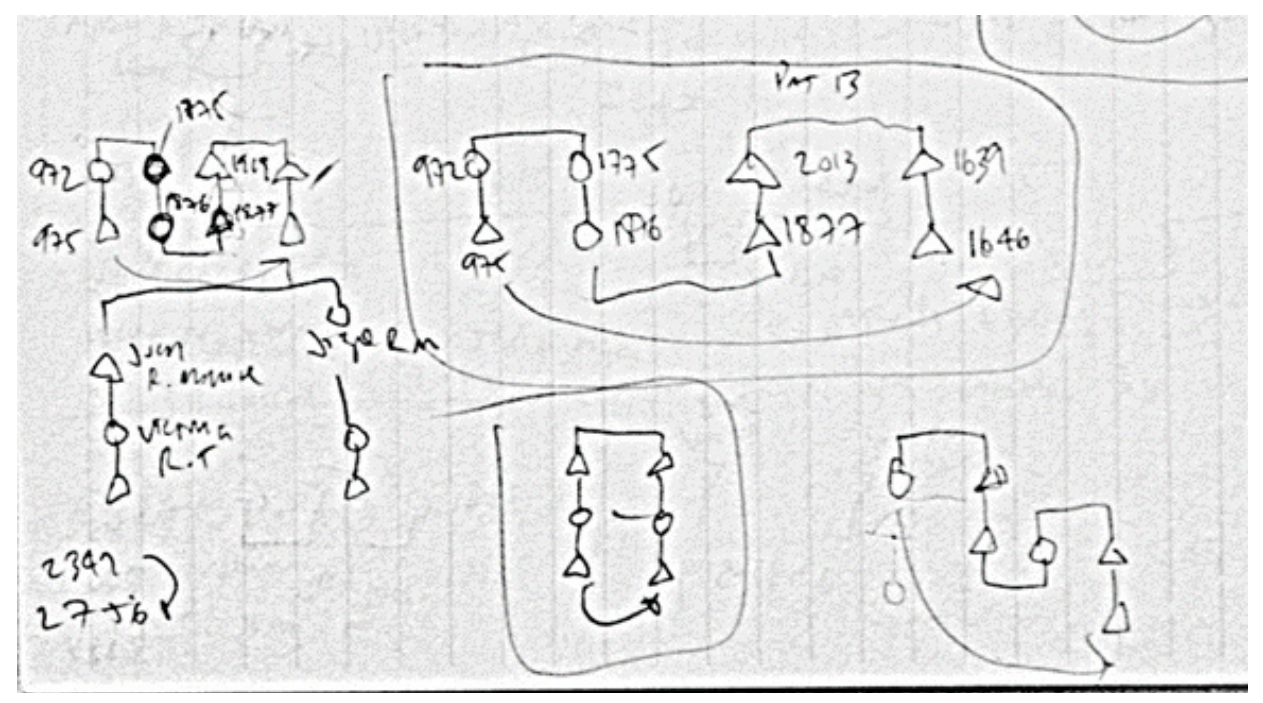

Cesiones de derecho y relación de parentesco. Lectura: se presentan cuadros genealógicos estándares sobre los cuales indicamos con una flecha la dirección del traspaso de una tierra.

Fuente: Extracto diario de campo Rapa Nui 2011 del autor.

Puck integra la visualización de GeneaQuilt ${ }^{9}$ que permite representar grandes sistemas genealógicos. La visualización de esta aplicación permite, entre otras funciones, identificar la densidad de la descendencia producida por un individuo en el seno del corpus. En nuestro caso nos serviremos de esta visualización para descifrar cómo los grupos de parentesco rapanui se arraigaron en el sector de Hanga Roa (Figura 2). 
Figura 2. Visualización con GeneaQuilt del Corpus genealógico rapanui

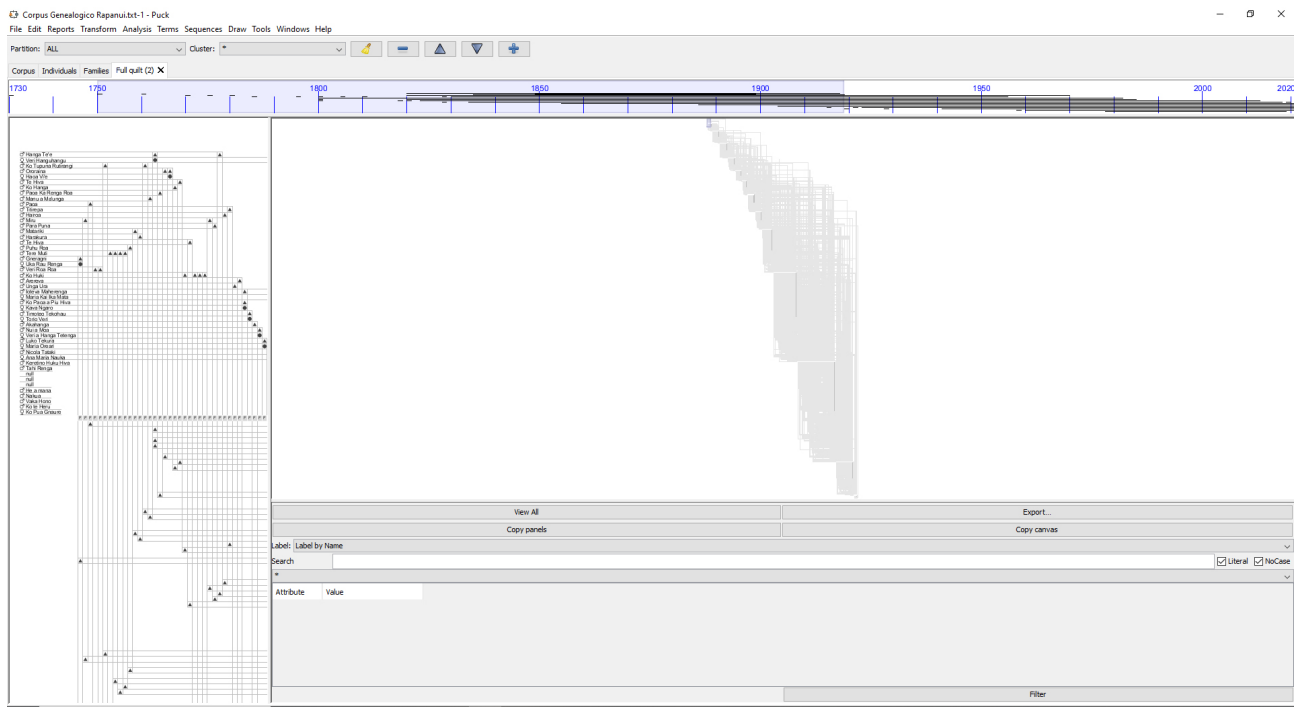

Lectura: en el cuadro de la izquierda se presentan los detalles del corpus indicando a los individuos (nombre y sexo). A la derecha, se observa el esquema en red de la totalidad del corpus. En este modelo de red, la sección superior corresponde a las generaciones más antiguas y la sección inferior a las más recientes. En la parte superior de la visualización se presenta una línea de tiempo.

Fuente: Captura de pantalla realizada por el autor.

Ambas herramientas nos han permitido analizar el largo de nuestro corpus genealógico asociado a los documentos de dominio y tenencia de tierras utilizados en Rapa Nui. Estos documentos corresponden a los 510 títulos provisorios otorgados entre 1921 y 1975 por la administración chilena a los rapanui y las 1.539 cesiones de derecho realizadas por los rapanui entre 1966 y $2011^{10}$.

\section{Breve historia del asentamiento en Hanga Roa}

A lo largo del siglo XIX, Hanga Roa, ubicada en la costa noroeste de la isla, fue la bahía preferida de los capitanes occidentales para el atraque de sus barcos, razón por la cual fue el lugar elegido por el padre Hippolyte Roussel para crear el villorrio de Santa María de Rapanui en 1866. Los rapanui conversos a la nueva religión fueron reasentados por los misioneros en la nueva villa entre 1868 y 1871 . El villorrio fue construido a unos 300 metros al interior de la bahía de Hanga Roa y la iglesia levantada sobre los cimientos de una casa de reunión de jefes. Las tierras en cuestión, que abarcaban unas 335 hectáreas, fueron compradas por Roussel el 5 de octubre de 1868 a cinco hombres rapanui (Vergara, 1939) ${ }^{11}$. Según el mapa de la división de los mata establecida por Routledge (1919, Fig. 91), el villorrio se encuentra en el territorio de los Marama, uno de los clanes aliados con los Miru durante la primera mitad del siglo XIX. 
El número de habitantes del villorrio osciló en el tiempo. Si en 1868 prácticamente todos los rapanui habían sido desplazados a esta zona, en 1872, después del gran éxodo a Tahiti y Mangareva (Muñoz, 2017a), el villorrio estaba deshabitado. Al mismo tiempo, la cercana bahía de Hanga Piko y las zonas aledañas a Mataveri -donde el colono francés Dutrou-Bornier había construido su casa- eran ahora los lugares poblados (Loti, 2006 [1872]). Durante los años en que Alexander Salmon (1879-1888) administró la estancia ovejera de la Maison Brander, las principales actividades se habían trasladado a Vaihu, en la costa sur. Aunque varios rapanui habían regresado a sus antiguas tierras a lo largo de la costa, seguían yendo a Hanga Roa para la misa dominical celebrada por los catequistas educados en Mangareva o Moorea.

Fue durante los primeros años de la administración chilena cuando los isleños, en ese momento no más de 250 personas (McCall, 1976), fueron encerrados en un área de 600 hectáreas, correspondiente a las antiguas tierras de la misión católica que el Estado chileno creía haber comprado (Vergara, 1939). Fue aquí donde los rapanui construyeron sus casas, arraigaron a sus descendientes y establecieron los consensos necesarios para apropiarse de dicho espacio, sobrepasando el principio de anterioridad. Entre 1886 y 1914, la zona de Hanga Roa se transformó en el nuevo henua poreko ranga, es decir, el lugar donde nacieron los ancestros (Métraux, 1971 [1940]).

\section{Arraigo en territorio Marama}

Con la evangelización y el desplazamiento de toda la población al territorio de los Marama, personas pertenecientes a clanes rivales se encontraron viviendo juntas, por lo que los isleños debieron ajustar sus relaciones de parentesco a esta nueva modalidad de residencia. Es lo que trataremos de dilucidar en esta sección.

En su estudio del censo de Hanga Roa de 1886, McCall (1976) identifica las filiaciones mata de una gran parte de los individuo ahí anotados: 17 hombres y nueve mujeres eran Miru; tres hombres y una mujer Rā; tres hombre y tres mujeres Haumoana; 11 hombres y cuatro mujeres Ure o He; dos hombres Ngatimo; 20 hombres y 14 mujeres Tupahotu; un hombre y una mujer Koro o Rongo; cinco hombres y tres mujeres Ngaure. Los Marama aparecen representados por siete hombres y cuatro mujeres ${ }^{12}$.

A partir de nuestro corpus genealógico, sabemos que, de las personas anotadas por McCall como Marama, cuatro hombres (Buenaventura Fati, Pakomio Maori, Ramon Hei y Rafael Ure Paringi) y las cuatro mujeres (Ana Katerina te Oho a Neru, Maria Pua Tahai, Maria Pua Kaingahiva y Angata Veri a Taki) tuvieron descendencia a lo largo del siglo XX. Tomemos dos ejemplos, uno masculino (Pakomio Maori) y otro femenino (Te Oho a Neru), para graficar la densidad de la descendencia Marama a principios del siglo XX (Figuras 3 y 4 ).

Con este ejercicio podemos concluir que, de las personas indicadas en el censo de 1886 como Marama y la descendencia que estos generaron, una o dos generaciones bastaron para que prácticamente todos los habitantes de Hanga Roa hacia 1914, momento en que Routledge realiza el primer registro genealógico, pudiesen adscribirse sea por línea materna, paterna o por alianza a un antepasado de este mata. 
Figura 3. GeneaQuilt de la densidad de la descendencia de Pakomio Maori [ 1830- 1908]

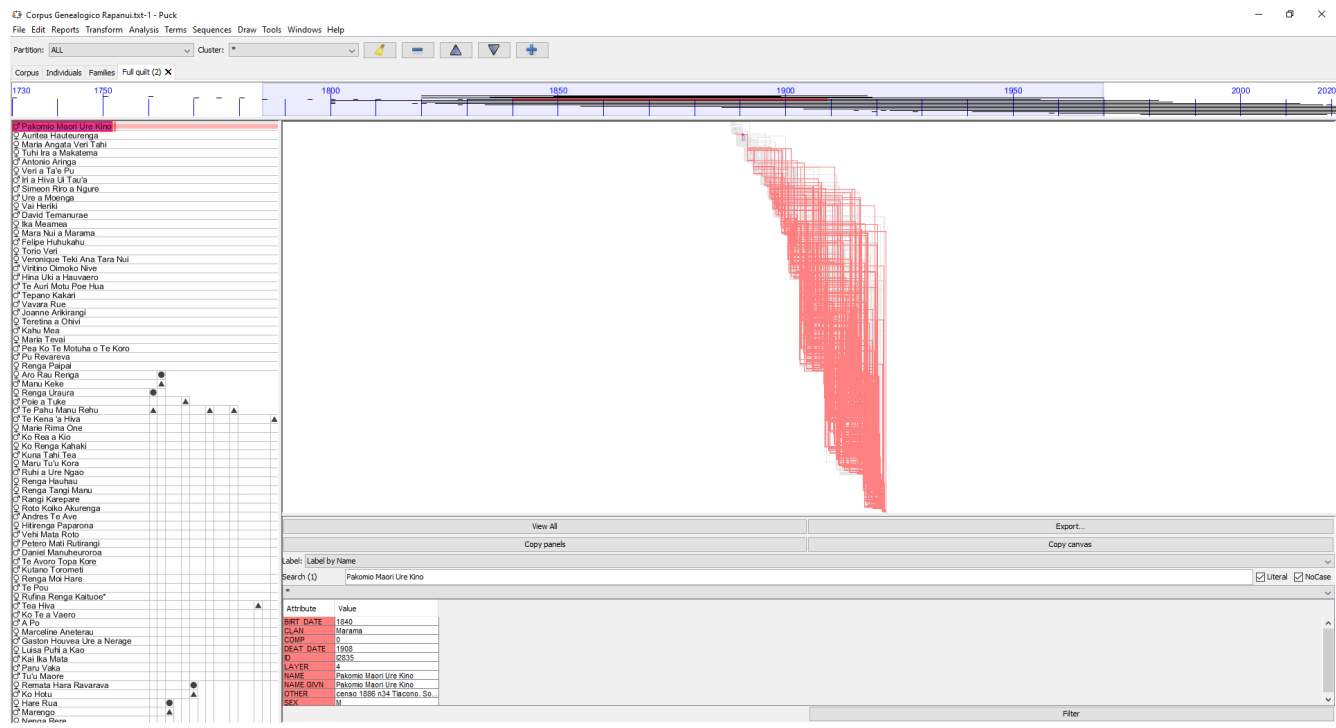

Sentido de lectura: a la derecha de la imagen todas las líneas, grises y rojas, corresponden al corpus genealógico en su totalidad. Las líneas rojas indican la descendencia de Pakomio Maori (esto debe ser leído de arriba hacia abajo).

Fuente: Realización propia.

Imagen 4: GeneaQuilt de la densidad de la descendencia de Ana Katerina te Oho a Neru [ 1825-1914]

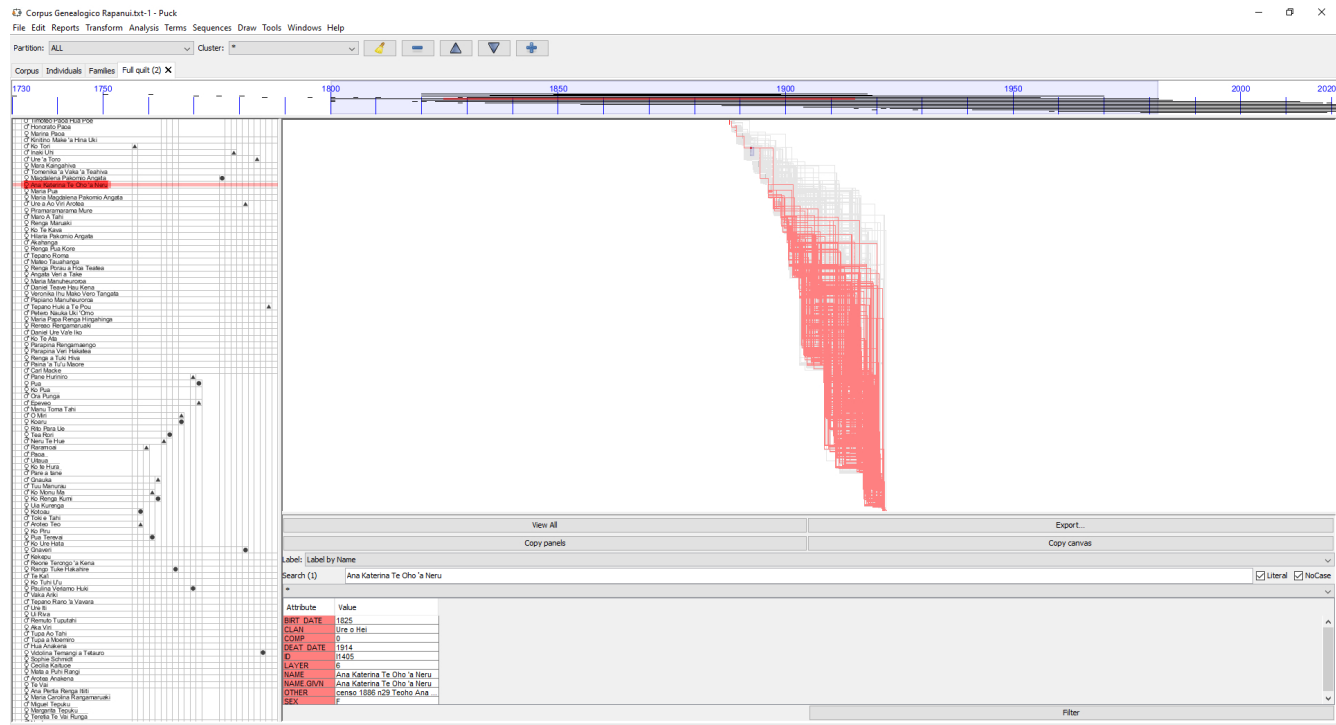

Sentido de lectura: a la derecha de la imagen, todas las líneas, grises y rojas, corresponden al corpus genealógico en su totalidad. Las líneas rojas corresponden a la descendencia de Ana Katerina Te Oho a Neru (esto debe ser leído de arriba hacia abajo).

Fuente: Realización propia. 


\section{Organización socio espacial}

Ahora bien, ¿cómo se distribuyeron en el espacio los nuevos grupos de parentesco? Tres documentos históricos nos permiten reconstruir la organización socioespacial del pueblo después de la anexión chilena: un detallado mapa realizado por la Armada en 1902, un dibujo realizado por Routledge en 1914 (1919) y el censo que el misionero Bienvenido De Estella realizó en 1918 (1921). Revisemos uno a uno estos documentos.

En el mapa de la Armada identificamos, a través de los pequeños cuadros negros que representan las casas, los tres sectores poblados (Figura 5). Comenzando en el edificio de la Iglesia (Church, № 1), identificamos un grupo de 21 casas a los alrededores, divididas en un grupo de 16 hacia el norte (№ 2) y un grupo de 5 casas hacia el sur de la Iglesia (№ 3). Siguiendo el camino en dirección al muelle (№ 4), encontramos un conjunto de siete casas (№ 5) cercanas al cementerio. Estos grupos de casas constituyen la aldea de Hanga Roa. Siguiendo ahora el camino que conduce a "Mata-Veri" (№ 7), identificamos una agrupación de seis estructuras que corresponde al caserío de Moeroa (№ 6). 
Figura 5. Mapa de Hanga Roa de 1902

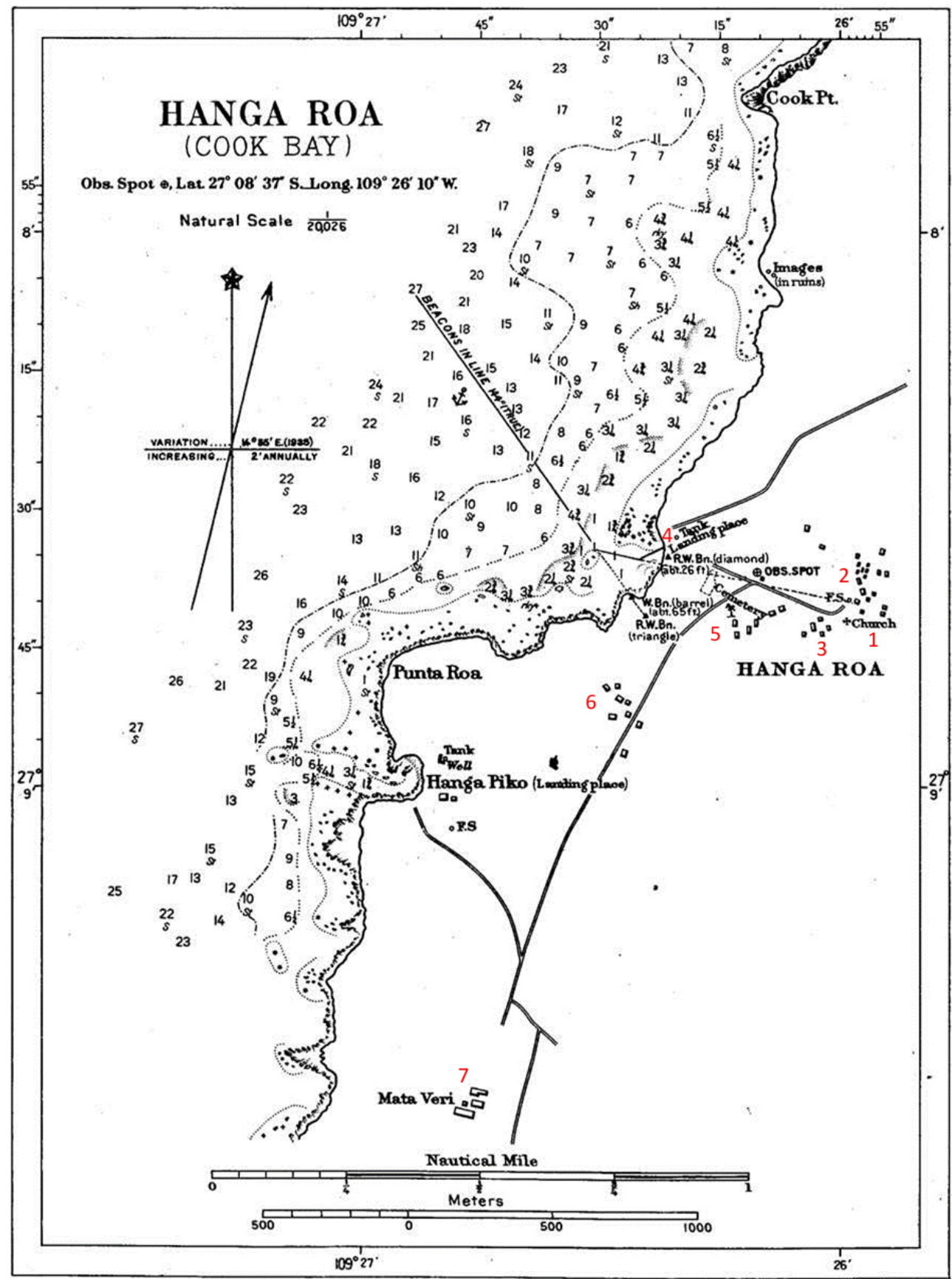

Fuente: Carta No 1119 U.S Hydrographic Office Publication 1925.

Los números fueron incorporados por el autor. 
El censo de 1918 nos da un detallado informe del número de casas, los miembros de cada hogar y las relaciones de parentesco al interior de cada uno de estos. Según este documento, en Hanga Roa existían 33 casas y un total de 171 habitantes; en Moeroa seis casas con 30 habitantes y en Mataveri, tres casas con 11 moradores. Este número de casas es muy cercano a las estructuras identificadas en el mapa de 1902. Por otra parte, el censo de 1918 nos permite determinar que la mayoría de las casas estaban habitadas por familias extensas, en las que se agrupaban individuos unidos por lazos genealógicos de entre cuatro $y$ tres generaciones.

Figura 6. Vista de Hanga Roa desde el norte, 1914

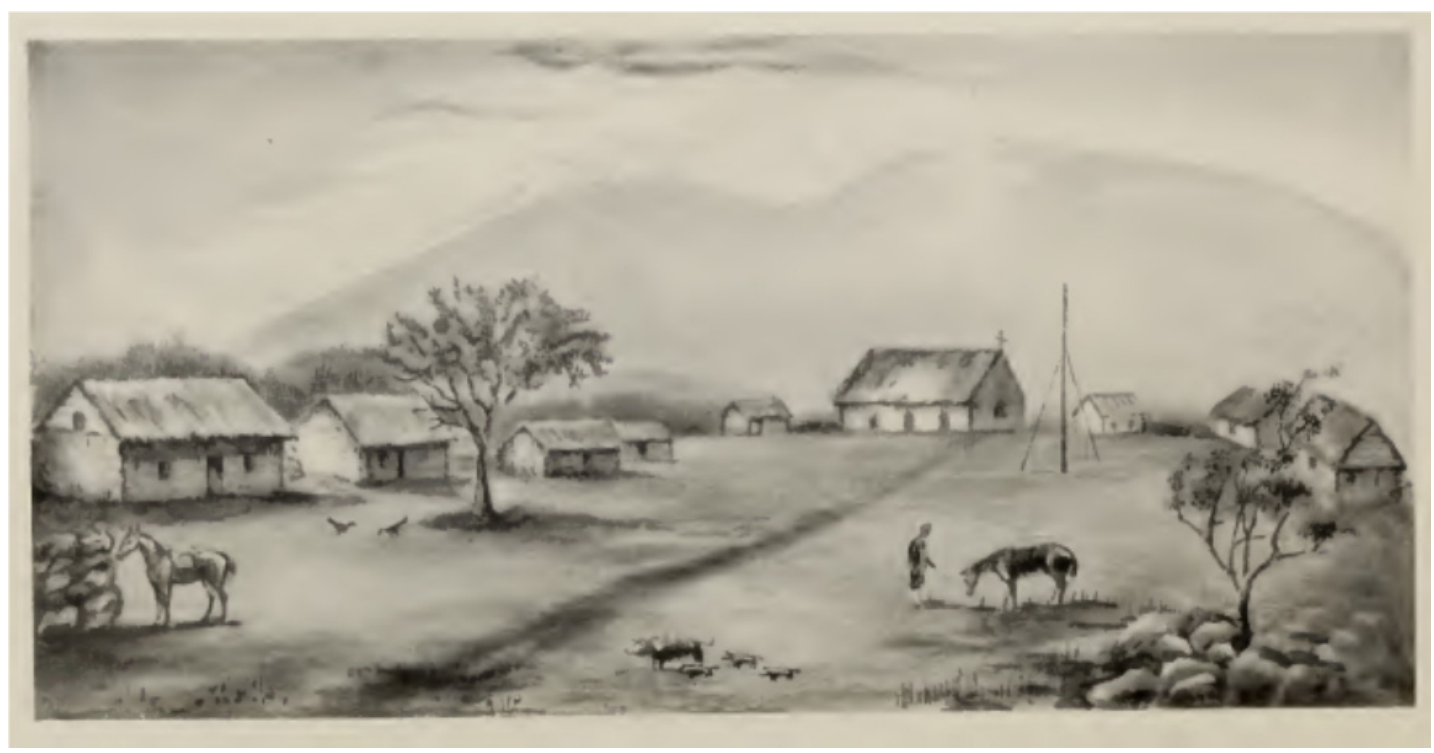

En el fondo del camino se aprecia el edificio de la iglesia y el mástil. Fuente: Routledge (1919, Fig. 27).

Si combinamos la información censal con la distribución geográfica de las casas siguiendo el mapa de 1902 y el dibujo de Routledge (Figura 6), donde el punto de vista corresponde a la sección que hemos indicado con el número 2 en el mapa de 1902, podemos suponer la existencia de una red de parentesco a partir de la cual se organiza el espacio. En el caso de Hanga Roa encontramos 20 casas habitadas por grupos familiares extensos: matrimonios con sus hijos ya casados y con su propia descendencia; y en 15 de estas casas los habitantes eran hermanos y hermanas que vivían con sus respectivos cónyuges. En el caso del sector Moeroa, también identificamos este modelo de familia extendida, donde las seis casas están pobladas por 11 personas emparentadas por descendencia y matrimonio (De Estella, 1921). 
La conclusión de este panorama es que en Moeroa y Hanga Roa los vecinos estaban estrechamente ligados por parentesco. En Moeroa, además, encontramos que el patrón de asentamiento se estructura en torno a un anciano de mata Marama (Romano Hei), mientras que en Hanga Roa, las afiliaciones mata de los habitantes es heterogénea. Lo anterior es indicativo que la ocupación del espacio en la reducción de Hanga Roa y Moeroa no siguió un modelo de distribución comunitario, es decir, que la totalidad del sector fuese concebido como propiedad colectiva por medio de los potenciales vínculos genealógicos con el mata Marama; ni tampoco un modelo centrado en los antiguos mata. Al contrario, el espacio se fragmentó por la ocupación de los nuevos grupos de descendencia diferenciados bajo formas patronímicas (Muñoz, 2017b), los cuales vivían en casas y parcelas relativamente bien definidas. Llamaremos a este patrón de asentamiento el modelo del hua'ai.

Cabe destacar que el dibujo de Routledge (Figura 6) deja suponer que aún no existían parcelas cerradas por cercos o muros, pero estos comenzarán a levantarse como resultado de la entrega de los títulos provisorios en las décadas venideras. De esta manera, el criterio mata es suplantado por este modelo centrado en el hua'ai. Con el pasar de los años cada hua'ai comenzó a ser asociado a parcelas y sectores claramente delimitados que serán más tarde reconocidos por documentos estatales.

\section{Extensión de Hanga Roa}

En 1917, la administración aumentó la superficie destinada a los rapanui para fines agrícolas, la cual pasó de 600 a 2000 hectáreas (Vergara, 1939). El efecto en el tiempo fue la amplificación del control familiar sobre dicho sector (Foerster et al., 2014). Así, en 1942, con ocasión de un estudio catastral de "propiedades" realizado por la Armada, se elaboró un nuevo plano (Figura 7) que puede ser leído como el modelo residencial de mediados del siglo XX (McCall, 1976). En este, cada parcela agrícola, la cual debía ser cercada, es identificada con un número y asociada a una persona, en su mayoría hombres (ver lista en Anexo). El plano muestra cómo el pueblo se expandió, lo que causó una desconcentración del espacio habitado y la separación entre un centro urbano habitado y una periferia agrícola. Por último, y siguiendo las conclusiones de Gómez (2004), cada parcela había sido entregada con un documento escrito que legitimaba el uso y el goce de dichas parcelas. 
Figura 7. Levantamiento topográfico y catastro de parcelas entregadas hasta 1942

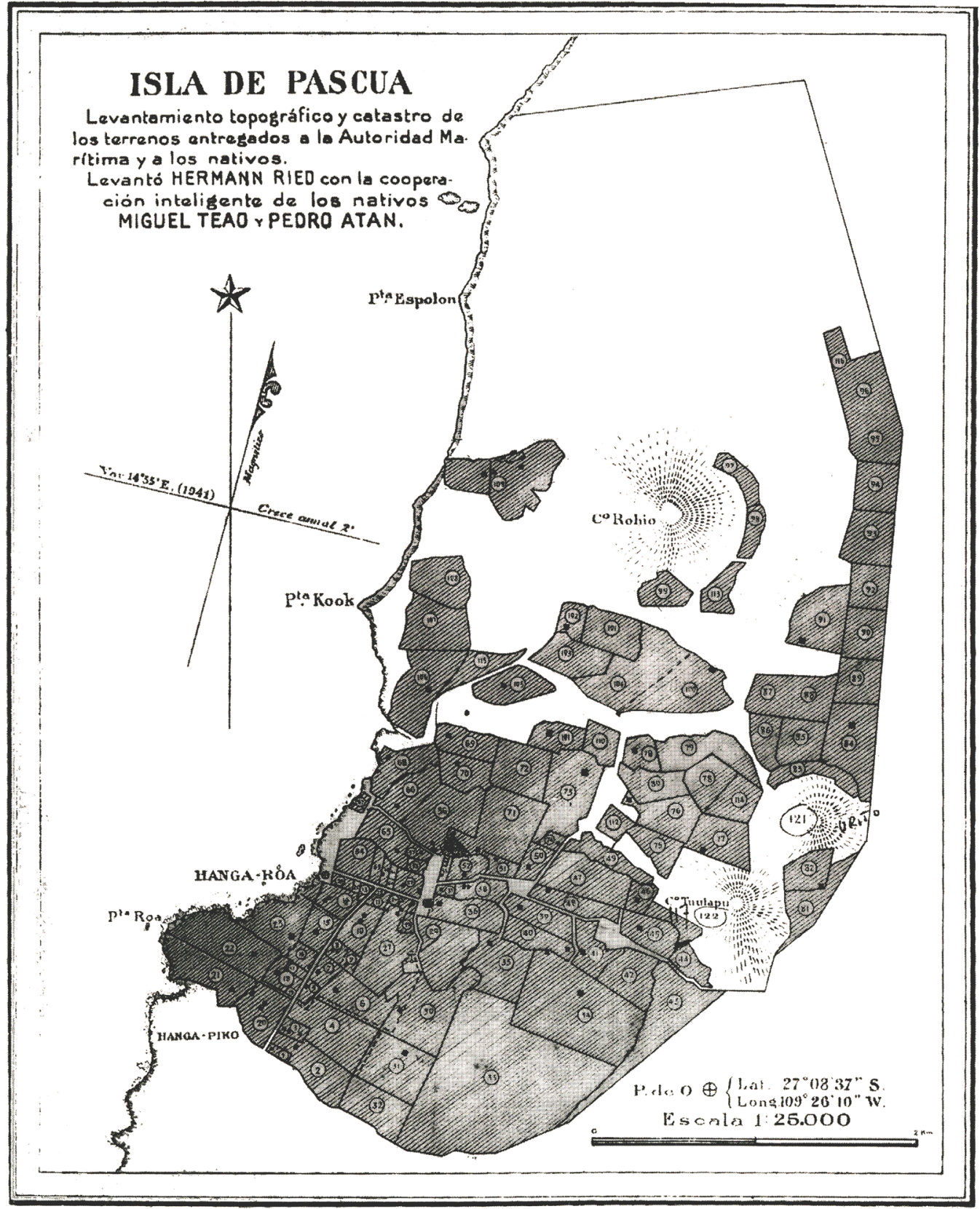

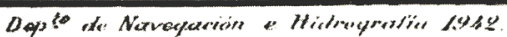

Fuente: Bienes Nacionales, Oficina provincial de Isla de Pascua. 
Pensamos que la ocupación de los grupos de descendencia sobre una misma parcela durante al menos tres generaciones va a alimentar un sentimiento de propiedad y de soberanía familiar en Hanga Roa y en Moeroa. Esto es una lógica de posesión muy cercana a lo observado por Firth (1936) o Bambridge (2009) en otras sociedades polinésicas donde la anterioridad y la permanencia prolongada de un grupo de descendencia sobre un mismo espacio legitimaban la ocupación. Al modelo del hua'ai, debemos adjuntar dos hechos capitales que contribuirán en la consolidación de la apropiación rapanui: la herencia y la aplicación de instrumentos estatales. Estos últimos, desde nuestro punto de vista, fueron leídos por los rapanui como instrumentos legitimantes frente a otros rapanui, antes de ser instrumentos legitimantes ante el Estado. Esto porque, no habiendo colonos en la isla y sabiendo que todos los rapanui vivían sobre un territorio Marama, el uso de los instrumentos estatales permitía inscribir la ocupación tanto en las memorias orales como en las escritas. Estos documentos actuaron fijando en el tiempo el registro de dicha propiedad a nombre de individuos que tuvieron descendencia, independiente de una eventual filiación Marama, que podía ser reclamada por otros rapanui. En fin, son estas parcelas, subdivididas por los rapanui bajo criterios ligados al parentesco, las que dieron origen a los actuales barrios de Hanga Roa.

\section{Instrumentos oficiales}

Con el pasar de los años se produce un profundo arraigo de los hua'ai en la zona de Hanga Roa y Moeroa. Este arraigo se verá reforzado por la política aplicada por la administración chilena. Esta consistió en dos procedimientos. Primero, el
Estado impone el principio colonial de terra nullius al inscribir la totalidad de la isla a nombre del fisco en 1933 (Rochna, 1996), negando el principio rapanui de anterioridad en la ocupación y las memorias genealógicas. El segundo consistió en la entrega de una serie de documentos escritos que autorizaban el uso, el goce y la propiedad de las parcelas del pueblo. Estos instrumentos son: los títulos provisorios, las actas de radicación, los títulos de dominio y las cesiones de derecho. Cada instrumento puede ser asociado a una época y ser leído desde la lógica rapanui sobre la tenencia y la propiedad inscrita en los hua'ai y que les otorga o no legitimidad.

\section{La larga política de los títulos provisorios}

En 1917, en el contexto del litigio por la propiedad que enfrentaba al Estado de Chile y la Compañía Explotadora de Isla de Pascua (CEDIP), una misión consultiva debía estudiar los procedimientos para establecer el dominio de los rapanui (Vergara, 1939; Foerster et al., 2014). Como el Estado se consideraba propietario de toda la isla desde la anexión, los comisionados propusieron dos fórmulas para solucionar el tema. La primera era considerar a los rapanui como colonos, aplicando las leyes que permitieron la colonización del sur de Chile por extranjeros. La segunda consistía en utilizar la Ley de Radicación de 1866, que creaba reservas indígenas. Ninguna ley fue promulgada para la radicación de los rapanui (Foerster et al., 2014) y, como es sabido, la solución del litigio entre el Estado y la CEDIP fue la inscripción de la superficie de la isla en el conservador de bienes raíces de Valparaíso como terreno fiscal (Vergara, 1939), incluidas aquellas tierras en las que vivían los rapanui desde al menos 1902 . 
Es en ese contexto que, a partir de 1920, los agentes coloniales iniciaron un proceso de regulación de la tenencia entregando a los rapanui los documentos conocidos como títulos provisorios. Estos actuaron como "una suerte de amalgama entre el sistema de reducción [que conocieron los Mapuche] y el establecimiento de colonias [extranjeras]" (Foerster et al., 2014 p. 74). Ahora bien, ¿cuáles son las características de estos títulos?

Figura 8. Título Provisorio: Cesión Provisoria de Terreno a León Laharoa Moeroa (1928)

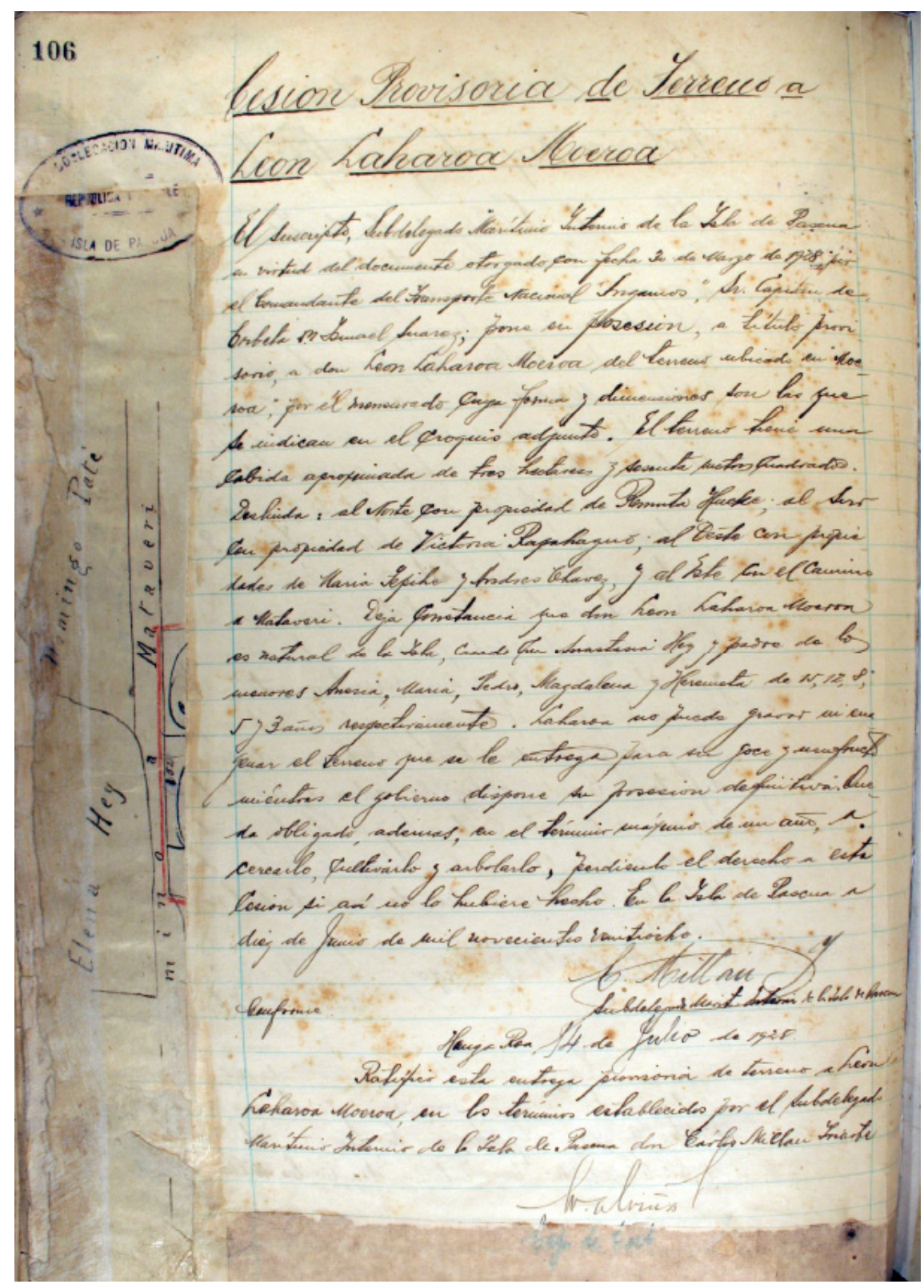

Fuente: Intendencia de Valparaíso, vol. 919, f. 106. 
En los títulos distinguimos que se trata de entregas individualizadas, a nombre de una persona considerada "natural de la Isla de Pascua". Se precisan además las dimensiones y los límites del terreno, y se señalan los nombres de los vecinos que son anotados como propietarios. La gran mayoría de estos títulos se acompaña de un croquis del terreno. Por otra parte, queda expresamente indicado que el beneficiario adquiere las obligaciones de cercar y cultivar, so pena de perder la cesión, así como, también, de no poder enajenar el bien cedido. Ambos elementos muestran que, a pesar que cada vecino es llamado "propietario", el tipo de derecho que estaba siendo reconocido era el de goce y uso.

La entrega de estos títulos fue un simple procedimiento administrativo. El interesado debía dirigirse a la Oficina de la Subdelegación Marítima y solicitar el título sobre una tierra anotada como "desocupada" o "vacante" (Rochna, 1996). Por otra parte, como lo concluye el estudio de Gómez (2004), los primeros títulos provisorios parecen haber sido entregados sobre las parcelas que las personas ya ocupaban. Es aquí donde el criterio de permanencia en la ocupación del hua'ai adquiere legitimidad escrita.

Cabe destacar que, si bien los rapanui podían tener un cierto margen de negociación en las solicitudes de los títulos, los criterios de entrega variaban según el juicio de cada agente colonial. En las entregas de 1931, por ejemplo, se indica que un "natural de la isla" podía obtener un título por estar casado y tener hijos o porque había mantenido una "conducta ejemplar"13. Posterior a ello, existen títulos donde se estipula que de cometer "alguna falta grave" el "beneficiario" perdería la cesión. También se agregó que el "beneficiado" adquiría la obligación de ceder a sus hijos parcelas de 5 hectáreas en la medida que se fueran casando, hasta que el beneficiario "original" alcanzara para sí una parcela con estas dimensiones, "las que corresponden a todo jefe de hogar"14. De este modo, en la medida que los rapanui solicitaban validar los títulos al pasar los años, estas nuevas disposiciones se iban adjuntando. Los criterios que cada subdelegado incorporó muestran que las tierras llegaron a ser, además de un medio de subsistencia, un criterio de control social y un objeto de don para el matrimonio.

Lo anterior produce un doble efecto sobre la tenencia. En primer lugar, si bien esta es inscrita a modo individual, el uso y el goce fueron ejercidos por el hua'ai. Esto se expresaba, en lo concreto, cuando el detentor del título autorizaba a sus hijos casados a edificar sus casas en la parcela inscrita a su nombre. Este patrón aparece ya en el censo de 1918 y fue observado por McCall en los años setenta (McCall, 1976). En segundo lugar, con la creación de la figura de las "parcelas de matrimonio", a partir de los años cuarenta, las nuevas parejas podían solicitar un título sobre una parcela desocupada o vacante (Zurob, 2011). De este modo, los rapanui tenían acceso a la tierra por don de matrimonio de los padres y por "derecho de jefe de hogar" ante la institución colonial. Concordamos con la conclusión de Gómez (2004) en cuanto que:

Los títulos provisorios [...] tuvieron la virtud de adaptar la tradición que acerca de la propiedad los pascuenses tenían, que si bien no es propiamente individualista como el enfoque jurídico occidental, no es tampoco una cosmovisión comunitaria (p. 3).

Esta política de títulos provisorios duró cerca de sesenta años (los últimos títulos provisorios 
se entregaron en 1975), por lo que implicó al menos a tres generaciones de isleños. Sumemos a ello que los primeros títulos fueron entregados por terrenos ya ocupados por los rapanui, al menos desde la reducción en Hanga Roa. Por estas razones, difícilmente se puede considerar que los rapanui integraron el concepto de que se les entregó derechos de uso y goce provisorios, al contrario, esta dilatación en el tiempo creó la idea de que dichas tierras eran de los hua'ai a través del criterio de la residencia prolongada y la anterioridad a la aplicación de los procedimientos estatales. Así, al menos, lo conservaron las memorias familiares y los documentos escritos. De estos hechos, pensamos, vendrá el valor de propiedad y veracidad que los isleños otorgan hoy a los títulos provisorios ${ }^{15}$.

\section{Cambio en la política estatal sobre el dominio}

Con la aprobación de la Ley 16.411 en 1966, que incorpora a Isla de Pascua a la administración civil, se produce un cambio en la política de tierras. Esta ley, en su Artículo 38, y el Decreto № 961 del 16 de junio de 1966 establecieron que el presidente de la República tenía la facultad de entregar "títulos de domino" a los habitantes de Isla de Pascua, los que podían ser chilenos no rapanui. Para ello, se utilizarían las leyes y normativas destinadas a la colonización (Rochna, 1996). El procedimiento consistía en la entrega de un título provisorio o un acta de radicación, con lo que se creó la figura de la concesión del bien público. El beneficiario debía construir una casa habitación, cercar el terreno y crear una vereda, para luego, y según los plazos estipulados, recibir el título de dominio que lo declaraba "poseedor regular".
Entre 1966 y 2008 se entregaron 145 actas de radicación, concentradas mayoritariamente entre los años 1966 y 1970 con un total de 43 actas; y entre los años 2001 y 2008 con otras 51 (MBN, 2011). Cabe destacar que con dichos documentos se seguía entregando un derecho de uso y goce y no el de propiedad. Sin embargo, se esperaba que fuesen ratificados más tarde como títulos de dominio. A diferencia de los títulos provisorios, algunas actas de radicación fueron entregadas a nombre de grupos de personas, en su mayoría parientes, pero también a organizaciones territoriales, como las juntas de vecinos. En 1975, el dictador Augusto Pinochet entregó 182 títulos provisorios, todos fechados el 24 de enero y bajo los mismos principios utilizados por la Armada (MBN, 2011). En 1979, aún bajo dictadura militar, se dio inicio a un nuevo proceso de atribución de dominio a través del Decreto 2.885, aún en vigor en lo substancial, donde se fomenta la creación de la propiedad individual.

Los primeros títulos de dominio se entregaron en $1981 \mathrm{y}$, curiosamente, solo un terreno fue inscrito por un chileno no originario de Rapa Nui. Rochna (1996) explica que este decreto ocasionó un conflicto con el Estado y dentro de la misma comunidad insular. Una buena parte de los isleños se organizó bajo una nueva instancia de representación, el Consejo de Ancianos, liderado por Alberto Hotus y Juan Chávez (Hotus et al., 1988; Rochna, 1996; Fischer, 2005). Los principales argumentos contra el decreto refirieron a la inscripción fiscal de 1933 y a la entrega de derechos de propiedad individual. Según Hotus et al. (1988), esta definición atentaba contra el principio básico del derecho tradicional rapanui que implicaba una visión comunitaria de la propiedad. Sin embargo, otra parte de la comunidad validó e hizo uso del decreto. En un 
contexto de rápidos cambios sociales y económicos iniciados en los años sesenta, las tierras se transformaron en un bien de inversión (Porteous, 1981). De acuerdo con Rochna:

\begin{abstract}
Los que apoyan el decreto [eran] principalmente los sectores más prósperos de la isla, personas relacionadas con actividades empresariales, como turismo y comercio, y algunos isleños que [tenían] a su cargo servicios públicos. Para ellos la ley constituía una oportunidad de darle curso a la iniciativa individual [...] sin el temor de perder sus inversiones por intervención familiar [...] se les abre la posibilidad de adquirir más de un terreno a través de las cesiones de derecho que en realidad encubren compras, o la acumulación de títulos gratuitos sobre terrenos fiscales. (1996, pp. 55-56)
\end{abstract}

Entre 1981 y 1989 se realizaron 365 inscripciones de dominio. Sin embargo, para 1988, $59,7 \%$ de las tierras no estaban inscritas bajo esta modalidad (Rochna, 1996). El decreto de 1979 estipulaba que todo habitante de la isla habría regularizado la tenencia en el lapso de un año. Sin embargo, este plazo fue modificado en varias oportunidades entre 1981 y 1989. Para Rochna (1996), el hecho de que los rapanui no ejercían el derecho otorgado demostraba la poca aprobación de esta medida.

Con la Ley Indígena de 1993 (CONADI, 2011) volverán a cambiar algunos aspectos importantes de las cesiones de tierras. El principal de ellos es la creación de la Comisión de Desarrollo de Isla de Pascua (CODEIPA), quien recibió importantes atribuciones en esta materia ${ }^{16}$. Sin embargo, producto de las desavenencias entre los rapanui en relación con la recuperación del dominio bajo un modelo de propiedad privada o comunitaria y con la discusión sobre la adquisición de la condición indígena, esta ley comenzó a aplicarse en Rapa Nui recién en 1998. Recordemos que el proyecto de ley indígena original contemplaba tres criterios para adquirir la calidad indígena ${ }^{17}$. Si bien estos criterios se aplicaron al resto de los pueblos indígenas (reconocidos como etnias), los rapanui lograron que el criterio de la autoidentificación de los cónyuges no se considerara en su caso. Con los argumentos de la exigua cantidad de tierras dada la condición insular y el "valor afectivo que la tierra tiene para el rapanui" (Hotus et al., 1988; BCN, 1998), los líderes de la época lograron convencer a ciertos senadores para que el reconocimiento de la calidad indígena se efectuase solo a través de los criterios ligados a la descendencia (Muñoz, 2014). Como lo explica Gómez (2019), "la etnia rapanui es la única que no contempla la posibilidad que un chileno cualquiera pueda autoidentificarse como rapanui" (p. 107). Con ello, los rapanui lograron excluir a chilenos no rapanui del acceso a la tierra. De este modo, la atribución de tierras y ser miembro de la etnia rapanui se presentan como un mismo y único asunto.

Resuelto el problema de quiénes serían considerados como rapanui a través de la Ley, la comunidad insular se confrontó a dos ideales sobre la propiedad de las tierras, uno defendido por el Consejo de Ancianos de la época, en que esta es descrita como comunitaria y donde la tierra poseía un valor corporativo y afectivo (Hotus et al., 1988), y otro levantado por el naciente empresariado turístico, planteada como un valor de propiedad familiar o individual. Como veremos más adelante es este último principio el que ha prevalecido en la práctica.

Entre 1979 y 2008 se entregaron 973 títulos de dominio, de ellos solo $9 \%$ se efectúo entre 1990 y 2005, en la denominada "Primera Etapa de Restitución de Tierras a la Etnia Rapanui" (MBN, 2011, p. 1). El proceso de desafectación se congeló entre 2007 y 2010 al entrar en 
discusión en el Senado un nuevo estatuto de administración para la Isla, el que a la fecha aún no ha visto su aprobación. Sin embargo, en 2010 el presidente de la época, Sebastián Piñera, entregó 26 títulos de dominio ${ }^{18}$ y hacia finales de su mandato entregó otros $60^{19}$. En 2012, el Estado quiso dar curso a la segunda etapa de restitución de tierras, a lo que los dirigentes políticos locales se opusieron por no haberse resuelto la inscripción fiscal de 1933. En 2014, el Estado intentó una vez más activar un plan que contemplaba la desafección de cerca de $25 \%$ de las tierras fiscales disponibles, en 256 parcelas de 2,5 hectáreas en la zona de Vaitea, pero la iniciativa fue rechazada.

Hasta la fecha el Estado no ha sometido a revisión la entrega de tierras como propiedad individual $y$, como veremos en las secciones siguientes, la gran mayoría de los rapanui han continuado considerando las tierras como un asunto de los hua'ai, lo que limita, en ciertos casos, la noción de arbitrariedad del concepto de propiedad individual. En este sentido, la concepción rapanui de la propiedad debe ser entendida como un hecho centrado en el hua'ai y no como una noción abstracta de lo comunitario. La relación entre hua'ai y propiedad de las tierras subentiende una lógica de segmentación de los grupos de descendencia en la herencia. Volveremos a ello.

\section{La plasticidad de las cesiones de derecho}

Ante la negativa de los rapanui de adquirir los títulos de dominio, una buena parte de los procedimientos empleados por ellos para transferir derechos sobre las tierras han sido las cesiones de derecho. Con este procedimiento, los derechos de propiedad individuales se transforman de facto en un derecho de uso y goce bajo supervisión del cesionario, so pena de ser disuelto. De esta manera, las tierras pueden seguir operando como un mecanismo de control social y como objeto de don, al igual que lo fueron con los títulos provisorios y, seguramente, como lo hacían antes de la aplicación de estos instrumentos. En opinión de Gómez (2004):

\begin{abstract}
Las cesiones de derecho están altamente legitimadas desde los puntos de vista tanto jurídico (como costumbre jurídica), como social, económico y cultural. Me parece observar que las personas en general y no sólo cedentes y cesionarios ven y sienten estos instrumentos como verdaderos títulos de dominio no obstante existir la conciencia que finalmente es el Fisco chileno el propietario único y garantes de las ocupaciones. (p. 3)
\end{abstract}

Entre 1966 y 2011 se realizaron 1.579 cesiones de derecho. Este hecho muestra que, en la práctica, estos instrumentos han venido a remplazar los títulos de dominio, dejando la noción de propiedad individual en un paréntesis jurídico. Esto, puesto que la cesión es un instrumento sui generis y no un título de propiedad (Gómez, 2004). Sin embargo, estas cesiones son suficientes para acceder a ciertas ayudas estatales o para la definición de la herencia. Por otra parte, los padres o abuelos rapanui recurrieron a estas para establecer de qué manera ellos distribuirían sus tierras entre su descendencia. Lo que antiguamente se hacía en forma oral, ahora se deja por escrito (Zurob, 2011). Estas cesiones se ajustaron, entonces, a las lógicas de herencia rapanui, pero también se superpusieron a la normativa civil chilena de la herencia mortis causa.

Por último, las cesiones de derecho han sido utilizadas para ocultar las compra-ventas de tierras. Una nueva faceta es que hoy las tierras 
son bienes de mercado. Cabe señalar que la Ley Indígena prohíbe las ventas o arriendos de tierras indígenas a personas no indígenas (Ley 19.253, Art. 13), por lo tanto, este mercado de tierras se desarrolla, en teoría, solo entre personas de origen rapanui. El tema de las ventas de tierras entre rapanui amerita un estudio profundo, puesto que existen hoy discursos yuxtapuestos: algunos las defienden como un derecho de resguardo frente a la intervención familiar ("si la tierra es mía, la puedo vender"), mientras que otros, si bien reconocen que la posibilidad de la compra-venta está legitimada por la ley, estiman que la práctica es altamente negativa ("la tierra no es mía, es de mis ancestros, ¿cómo la voy a vender?, eso está mal”). El tema no es menor, ya que la concentración de tierras en pocas manos podría llegar a ser uno de los asuntos más complejos y conflictuales en un futuro cercano de la sociedad insular.

\section{Las lógicas de acción en la herencia rapanui}

La pregunta por las maneras en que los rapanui se distribuyeron las tierras que habitaban resulta clave para entender la configuración histórica de la sucesión y la herencia. En la sección anterior hemos podido reconstituir un panorama de cien años de inscripción de la tenencia a través de los dispositivos estatales. Se desprende de este análisis que, al menos los títulos provisorios y las cesiones de derecho, fueron reapropiadas por los rapanui como elemento legitimante de la posesión, tanto frente al Estado como frente a otros rapanui. Estos dos instrumentos, pensamos, se ajustaron a la lógica rapanui sobre la tenencia: las tierras como propiedad del fundador de una línea de descendencia (principio de anterioridad), quien distribuyó derechos de uso, guardando para sí el título original. Revisemos más en detalle cómo ha actuado el parentesco en la distribución de las tierras rapanui.

\section{Relaciones de parentesco en la fragmentación de los títulos provisorios}

Primeramente, la política de títulos provisorios permitió lo que Foerster et al. (2014) Ilaman la "proyección del sistema parcelario". En la medida que se entregaban nuevos títulos sobre sectores cada vez más apartados del pueblo, los rapanui ampliaron el control sobre las tierras, pero en cabidas desiguales (algunos se atribuyeron parcelas de 50 hectáreas, otros solo obtuvieron parcelas de tres hectáreas). Con el tiempo, los rapanui subdividieron las parcelas como sucesión, provocando lo que Foerster et al. (2014) Ilaman "la fragmentación interna del mapa parcelario". Estas divisiones se realizaron tanto en forma oral como por escrito. Respecto a los trazos escritos Foerster et al. (2014) concluyen lo siguiente:

Al revisar en detalle los 237 títulos provisorios [en realidad son 235] concedidos en el periodo [1947-1970] [...] se puede verificar que muchos de ellos corresponden a meras divisiones internas de parcelas por parte de los titulares hacia sus herederos o hijos de crianza y/o como ratificación de títulos anteriores. (p. 96, el destacado es nuestro)

Hemos analizado los documentos en cuestión para definir con mayor precisión las lógicas que operaron en las divisiones internas. Al clasificar los documentos por razón de la entrega, obtenemos resultados importantes. En su conjunto, de los 235 títulos, 209 (90 \%) corresponden a entregas por matrimonio, herencia o 
donación, donde 96 (41\%) son indicados como herencias, 82 (35\%) son entregas por matrimonio y 32 (14\%) son donaciones. La concentración de documentos entregados por dichos motivos nos permite demostrar la importancia que las relaciones de parentesco tuvieron a la hora de definir las divisiones internas de las parcelas. Por otra parte, con estos documentos podemos identificar algunas de las modalidades de fragmentación: quién ha heredado de quién, así como también quién ha donado a quién. Aclarar dichos nexos nos permite comprender la complejidad de las herencias de tierras, al menos en lo que concierne a la validación por vía escrita. Revisemos esto.
Los documentos señalados como herencia se concentran entre los años 1962 y 1963, es decir, 40 años después de las primeras entregas de títulos provisorios. Podemos suponer, entonces, que estos conciernen a los hijos y parte de los nietos de los primeros detentores de títulos provisorios. Del total de 96 documentos señalados como herencia, 43 se efectuaron en 1962; y 53 en el año siguiente. A continuación, presentamos las cadenas de parentesco involucradas en las herencias (Tabla 1).

Tabla 1. Cadena de parentesco en la herencia de los títulos provisorios (1962-1963)

\begin{tabular}{|c|c|c|c|c|c|c|c|c|}
\hline \multirow{2}{*}{$\begin{array}{l}\text { Relación de } \\
\text { parentesco }\end{array}$} & \multirow{2}{*}{\multicolumn{2}{|c|}{$\begin{array}{l}\text { Generación en relación } \\
\text { con ego dador }\end{array}$}} & \multirow{3}{*}{$\begin{array}{l}\text { Terminología } \\
\begin{array}{l}\text { korohua- } \\
\text { makupuna }\end{array}\end{array}$} & \multicolumn{2}{|c|}{ Frecuencia } & \multirow{3}{*}{$\begin{array}{r}\text { Total } \\
13 \\
\end{array}$} & \multirow{2}{*}{\multicolumn{2}{|c|}{$\begin{array}{l}\text { Porcentajes } \\
\text { Subtotales [\%] }\end{array}$}} \\
\hline & & & & 1962 & 1963 & & & \\
\hline \multirow{3}{*}{ Descendencia } & $\mathrm{G}+2$ & $\begin{array}{l}\text { Abuelo- } \\
\text { nieto }\end{array}$ & & 7 & 6 & & 13,54 & \multirow{3}{*}{82,28} \\
\hline & $\mathrm{G}+1$ & Padre-hijos & $\begin{array}{l}\text { matu'a-nga } \\
\text { poki }\end{array}$ & 16 & 27 & 43 & 44,79 & \\
\hline & $\mathrm{G}+1$ & Madre-hijos & & 14 & 9 & 23 & 23,95 & \\
\hline \multirow{2}{*}{ Colateralidad } & Go & $\begin{array}{l}\text { Hermano- } \\
\text { hermano }\end{array}$ & Taina & 0 & 1 & 1 & 1,04 & \multirow{2}{*}{3,2} \\
\hline & & Tío-sobrino & $\begin{array}{l}\text { matu'a keke- } \\
\text { gna poki }\end{array}$ & 0 & 2 & 2 & 2,08 & \\
\hline \multirow{3}{*}{ Alianza } & & $\begin{array}{l}\text { Esposo- } \\
\text { esposa }\end{array}$ & kenu-vi'e & 1 & 2 & 3 & 3,12 & \multirow{2}{*}{4,16} \\
\hline & $\begin{array}{l}\text { Suegro- } \\
\text { nuero }\end{array}$ & & $\begin{array}{l}\text { Hunavai- } \\
\text { hunona }\end{array}$ & 1 & 0 & 1 & 1,04 & \\
\hline & Adopción & & Hānai & 0 & 4 & 4 & 4,16 & \\
\hline Indeterminada & & & & 4 & 2 & 6 & 6,2 & \\
\hline Total & & & & 43 & 53 & 96 & 99,9 & \\
\hline
\end{tabular}

Fuente: Elaboración propia. 
Nuestra tabla muestra la tendencia que la herencia fue transmitida mediante relaciones de descendencia (82\%), principalmente de padre a hijos (44,79\%). Esto es señal de una inclinación agnaticia en la herencia. Sin embargo, el porcentaje de los títulos que las madres heredan a sus hijos $(23,95 \%)$ es revelador de un patrón de herencia bilineal. Esto permite observar cómo el sistema de parentesco rapanui de inclinación agnaticia se transforma en uno cognaticio (Muñoz, 2014). De este modo, $68 \%$ de los traspasos de tierras por herencia se dieron a través de relaciones de descendencia de tipo matu'a -nga poki. Las herencias dadas por abuelos, tíos, así como la incorporación de las relaciones de tipo hānai (adopción tradicional) reflejan también un patrón de herencia dentro de relaciones de parentesco extendido, las que abarcan también relaciones de colateralidad y de alianza.

Revisemos ahora las cadenas de parentesco identificadas en las donaciones de tierras (Tabla 2).

Tabla 2. Cadenas de parentesco en las donaciones de títulos provisorios (1962-1963)

\begin{tabular}{|c|c|c|c|c|c|c|c|c|}
\hline \multirow{3}{*}{$\begin{array}{l}\text { Relación de } \\
\text { parentesco }\end{array}$} & \multirow{2}{*}{\multicolumn{2}{|c|}{$\begin{array}{l}\text { Generación en } \\
\text { relación a ego } \\
\text { donador }\end{array}$}} & \multirow{3}{*}{$\begin{array}{l}\text { Términos } \\
\text { korohua- } \\
\text { makupuna }\end{array}$} & \multicolumn{3}{|c|}{ Frecuencia } & \multirow{2}{*}{\multicolumn{2}{|c|}{$\begin{array}{c}\text { Porcentaje } \\
\text { Subtotales [\%] }\end{array}$}} \\
\hline & & & & \multirow{2}{*}{$\begin{array}{r}1962 \\
1\end{array}$} & \multirow{2}{*}{$\begin{array}{r}1963 \\
1\end{array}$} & \multirow{2}{*}{$\begin{array}{r}\text { Total } \\
2\end{array}$} & & \\
\hline & $\mathrm{G}+2$ & Abuelo-nietos & & & & & 6,4 & \multirow{3}{*}{72,4} \\
\hline & $\mathrm{G}+1$ & Padre-hijos & $\begin{array}{l}\text { matu'a - } \\
\text { nga poki }\end{array}$ & 5 & 5 & 10 & 32 & \\
\hline & $\mathrm{G}+1$ & Madre- hijos & & 11 & 0 & 11 & 34 & \\
\hline \multirow[t]{2}{*}{ Colateralidad } & G0 & $\begin{array}{l}\text { Hermano- } \\
\text { hermano }\end{array}$ & Taina & 3 & 0 & 3 & 10 & \multirow{2}{*}{13,2} \\
\hline & $\mathrm{G}+1$ & $\begin{array}{l}\text { Tío- } \\
\text { sobrinos }\end{array}$ & $\begin{array}{l}\text { matu'a } \\
\text { keke- gna } \\
\text { poki }\end{array}$ & 0 & 1 & 1 & 3,2 & \\
\hline \multirow[t]{3}{*}{ Alianza } & & $\begin{array}{l}\text { Esposo- } \\
\text { esposa }\end{array}$ & kenu-vi'e & 0 & 0 & 0 & - & \\
\hline & & Suegro-yerno & $\begin{array}{l}\text { Hunavai } \\
\text { - hunona }\end{array}$ & 1 & 0 & 1 & 3,2 & \\
\hline & & Adopción & Hānai & 0 & 0 & 0 & - & \\
\hline Indeterminada & & & & 2 & 1 & 3 & 10 & \\
\hline Total & & & & 23 & 9 & 32 & 99 & \\
\hline
\end{tabular}

Fuente: Elaboración propia. 
Identificamos que las donaciones fueron efectuadas en una importante proporción desde los padre o madres a sus hijos (matu'a -nga pokı) (66\%), con una leve inclinación uterina (34\%), lo que nos permite reafirmar la hipótesis de la inclinación cognaticia del sistema de parentesco rapanui (Muñoz, 2014). Resulta importante señalar que, a diferencia de los títulos traspasados como herencia, los que suponen una relación post-mortem, las donaciones son realizadas necesariamente en vida. Esto implica, además, que las tierras fueron transmitidas posiblemente como un complemento a una futura herencia.

Resulta igualmente importante el hecho que estas tierras no fueron clasificadas como entrega por matrimonio, lo que muestra que el acceso se realizaba adjuntando las tierras recibidas desde la familia como herencia y don y aquellas entregadas por los agentes coloniales por matrimonio.
Observamos que las donaciones documentadas se inscriben dentro de las relaciones de parentesco extendidas (que incorporan las relaciones de colateralidad y alianza). Las donaciones realizadas por abuelos a sus nietos, así como los casos de donaciones de un suegro a su yerno (hunavai-hunona) son ejemplo de ello.

\section{Relaciones de parentesco en las cesiones de derecho}

Hemos indicado más arriba que los rapanui han privilegio los documentos conocidos como cesiones de derecho a la hora de transmitir derechos sobre las tierras. El análisis genealógico del conjunto de las 1.539 cesiones de derecho nos permite identificar con precisión cómo y entre quiénes estas cesiones han sido realizadas (Tabla 3 ). 
Tabla 3. Cadenas de parentesco en las cesiones de derecho

\begin{tabular}{|c|c|c|c|c|c|c|c|}
\hline \multirow{2}{*}{$\begin{array}{l}\text { Relación de } \\
\text { parentesco }\end{array}$} & \multirow{2}{*}{$\begin{array}{l}\text { Generación en } \\
\text { relación a ego } \\
\text { cesionario }\end{array}$} & \multirow{2}{*}{ Términos } & \multirow{2}{*}{ Frecuencias } & \multicolumn{4}{|c|}{ Porcentaje } \\
\hline & & & & \multicolumn{4}{|c|}{ Subtotales [\%] } \\
\hline \multirow{5}{*}{ Descendencia } & $\mathrm{G}+3$ & \multirow{2}{*}{$\begin{array}{l}\text { Korohua } \\
\text { Nuahine }\end{array}$} & 2 & 0,1 & & \multirow{5}{*}{56,2} & \multirow{11}{*}{82,8} \\
\hline & $\mathrm{G}+2$ & & 113 & 7,2 & & & \\
\hline & \multirow{3}{*}{$\mathrm{G}+1$} & Matu‘a Tane & 385 & 50,9 & \multirow{2}{*}{47,8} & & \\
\hline & & Matu'a Vahine & 370 & 49,1 & & & \\
\hline & & Hānai & 18 & 1,1 & & & \\
\hline \multirow{3}{*}{ Colateral } & $\mathrm{G}+1$ & $\begin{array}{l}\text { matu‘a keke- } \\
\text { gna poki }\end{array}$ & 131 & 8,3 & & \multirow{3}{*}{24,5} & \\
\hline & G0 & Taina & 218 & 13,8 & & & \\
\hline & G0 & Taina ke‘e & 38 & 2,4 & & & \\
\hline \multirow{3}{*}{ Alianza } & $\mathrm{G}+1$ & Hunavai & 4 & 0,2 & & \multirow{3}{*}{2,1} & \\
\hline & Cónyuge & $\begin{array}{l}\text { Kenu } \\
\text { Vi'e }\end{array}$ & 23 & 1,4 & & & \\
\hline & G0 & Taokete & 5 & 0,5 & & & \\
\hline $\begin{array}{l}\text { Otro vínculo } \\
\text { genealógico }\end{array}$ & & & 129 & 8 & & \multirow{2}{*}{\multicolumn{2}{|c|}{14,3}} \\
\hline $\begin{array}{l}\text { Sin relación conocida } \\
\text { a la } 5^{\text {ta }} \text { generación } \\
\text { ascendente }\end{array}$ & & & 100 & 6,3 & & & \\
\hline $\begin{array}{l}\text { Compraventa } \\
\text { declarada }\end{array}$ & & & 43 & 2,8 & & 2,8 & \\
\hline Total & & & 1.579 & 99,9 & & 99,9 & \\
\hline
\end{tabular}

Fuente: Elaboración propia.

Nuestro análisis de las cadenas de parentesco muestra que las cesiones se han realizado en estrecha relación con distancias genealógicas bien determinadas y concentradas en las relaciones de descendencia de tipo $\mathrm{G}+1$ $(47,8 \%)$, sin desconocer aquellas de tipo $\mathrm{G}+2$ $(7,2 \%)$, y que en su conjunto representa $56,2 \%$. Resulta importante notar que estas no se limitan solo a la cadena matu'a -gnapoki (padre-hijos/ madre-hijos) sino que abarcan una extensión de tres generaciones ascendentes desde la persona que recibió una cesión. La participación de mujeres resulta relevante, lo que nos lleva a considerar la importancia de los vínculos uterinos en el acceso a las tierras. Llama la atención que las relaciones de colateralidad han sido recurrentes (24\%), siendo las más representativas aquellas de tipo matu'e keke (8\%) y entre el grupo taina (13\%). Esto revela que las cesiones de derecho no son solo un asunto de la familia nuclear, sino que involucra un grupo de parentesco más amplio.

Al considerar una temporalidad generacional detectamos un procedimiento interesante. Varias de las tierras traspasadas bajo un principio de descendencia fueron luego traspasadas de manera lateral entre los hermanos 
(taina). Un ejemplo recurrente es el caso donde un hermano recibió la cesión de un terreno y que algunos años después procedió a entregar cesiones a sus hermanos menores o incluso a sobrinos. Por último, si bien menos recurrentes, las cesiones realizadas en cadenas de alianza demuestran de manera clara la imbricación en el acceso a la tierra de relaciones de parentesco en su forma extendida. En su conjunto, las relaciones de parentesco, tanto de descendencia, colateralidad y alianza, concentran 82,5 $\%$ de las cesiones de derecho entre los años 1966 y 2011.

Resta la pregunta sobre las compra-ventas de tierras. Con la información revisada podemos avanzar dos conclusiones. En primer lugar, las ventas no han sido siempre declaradas en las cesiones. La segunda, que las ventas se han realizado entre personas genealógicamente alejadas. Del conjunto, solo detectamos 41 cesiones declaradas como compras de terrenos, lo que equivale a $2,8 \%$ del total. Sin embargo, a partir de los documentos fechados en 1998 (cuando la Ley Indígena empieza a ser aplicada en la isla) detectamos un aumento progresivo de cesiones entre personas genealógicamente alejadas ( $8 \%$ de cesiones) y entre personas que no tienen ningún pariente en común antes de una $5^{\text {ta }}$ generación genealógica $(6.3 \%$ de casos). Nuestro análisis muestra que $14,3 \%$ de las cesiones fueron realizadas entre personas que no eran parientes cercanos. Este resultado nos permite proponer la hipótesis de que las ventas de tierras se realizan principalmente entre personas que nos son parientes y que aparecen ocultas en las cesiones de derecho. Esta faceta de las tierras como bien de mercado rompe con el control del hua'ai sobre estas, lo que se perfila como una nueva área de conflicto para los años a venir.

\section{Conclusión: la propiedad fragmentada}

Hemos estudiado un aspecto pocas veces aclarado con precisión sobre los traspasos de derechos de tierra entre los rapanui. Estas prácticas se justifican desde concepciones de la propiedad que mezclan principios reconocidos como propios, como lo son la anterioridad y la permanencia en el tiempo en la ocupación, pero aplicados y justificados con procedimientos estatales. Es importante resaltar que los dispositivos estatales que han sido privilegiados por los rapanui son aquellos que permiten que las tierras continúen siendo un objeto de don y un medio de control social hacia una descendencia, dos atributos reconocidos en los títulos provisorios y en las cesiones de derecho. Estos dos criterios se ven fuertemente afectados con la política estatal de entrega de títulos de dominio, que privilegia la figura de propiedad individual y, por lo tanto, que consagra el principio de arbitrariedad en la disposición y uso del bien.

En este escrito hemos podido ver que la larga política de entrega de títulos provisorios por parte del Estado y la plasticidad de las cesiones de derecho han sido leídas por los rapanui desde sus propias lógicas de parentesco. En esta lectura se han arraigado ciertos consensos sociales respecto a la propiedad, las formas de adquisición y las formas de herencia. Detengámonos en ello para concluir este trabajo.

Un primer consenso es que los rapanui se reconocen como los dueños legítimos de todas las tierras de la isla. Esto, tanto desde sus memorias genealógicas que conectan a los vivos con los antepasados y los antiguos mata (Muñoz, 2017b), como, tal como hemos visto aquí, a través de los mecanismos de apropiación y distribución de derechos de uso 
y goce sobre las parcelas en Hanga Roa. Este acuerdo social tiene que ver, además, con que los rapanui lograron excluir a los chilenos no rapanui de la tenencia de las tierras (Muñoz, 2014). Sin embargo, esta particularidad en el acceso a la propiedad se ve confrontado al hecho de que el Estado considera que toda la isla pertenece al fisco. Es aquí donde la definición de la naturaleza del derecho de propiedad es fuente de disputas a nivel local. En un plano discursivo, varios líderes rapanui han reivindicado la propiedad colectiva (Hotus et al., 1988), sin embargo, en la práctica, los instrumentos estatales empleados por los rapanui permiten observar una concepción fragmentaria de la propiedad. Esta es ejercida por los grupos de parentesco, los que aparecen bien determinados tanto por las formas patronímicas como por las memorias genealógicas (Muñoz, 2014, 2017b), las que, en asunto de tierras, son asociadas a un título provisorio.

Un segundo consenso es que las tierras se heredan. Hemos reconocido que históricamente esto se ha realizado por intermediación del parentesco, lo que implica una parte de aspectos comportamentales (Muñoz, 2014). Estos aspectos explican los grandes disensos en el seno de los hua'ai respecto a cómo la tierra debe ser dividida (sobre todo cuando hay personas excluidas de las herencias). Pero también, la herencia puede implicar la aplicación del código civil chileno, lo que demuestra la intersección de ambos sistemas jurídicos. Hemos visto que las tierras pueden ser donadas bajo principios que trascienden las solas relaciones de descendencia -pues involucran otras relaciones genealógicas- como también bajo nociones que desbordan los principios de propiedad individual fomentada por el Estado.
Un tercer consenso es que cada familia e individuo rapanui posee un derecho teórico a la tierra. Esto se ha podido observar tanto a través de las nociones de las tierras como objeto de don y de herencia, como a través de los criterios empleados por los agentes coloniales que fomentaron las subdivisiones internas de las parcelas en favor de los hijos casados. Hoy, todo rapanui tiene derechos sobre las tierras y los adquiere ya sea por don o cesión de sus familiares -los que pueden ser trazados dentro de una larga genealogía-, como beneficiario de la política de desafección del Estado o a través de la compra. Estas dos últimas maneras, claro está, restan injerencia a los hua'ai sobre las entregas de derechos. Los títulos de domino rompen así con el criterio rapanui en el que la propiedad y los usos de las tierras son un asunto del hua'ai. Ahora bien, cabe destacar que en la política estatal las decisiones sobre a quién se le otorga un nuevo terreno pasan también por resoluciones de la CODEIPA, institución híbrida compuesta por representantes de los diferentes ministerios y representantes electos por los rapanui. Saber de qué manera dichos representantes electos se encuentran también imbricados en los asuntos de sus propios hua'ai a la hora de determinar a los futuros beneficiaros de la política de tierras es un tema para otra investigación.

En la actualidad, los usos de las cesiones de derecho - sea por su facilidad en el otorgamiento, sea porque se ajustan a la idea del control parental sobre la tierra- han venido a remplazar, en la práctica, los títulos de dominio. De hecho, hasta 2011 existían más cesiones de derechos que títulos de dominio. Las cesiones de derecho, como se dijo, no otorgan un derecho de propiedad individual propiamente tal, al contrario, permiten un uso colectivo 
de una tierra adjudicada bajo un título provisorio a personas ya fallecidas. De este modo, el principio de arbitrariedad que la noción de propiedad individual conlleva se ve fuertemente limitado por el hecho que el beneficiado del título no puede ya ejercer los derechos reconocidos o controlar las decisiones respecto al uso, el goce y la distribución.

La conclusión es que las cesiones de derecho se han realizado hasta la fecha en estrecha relación con ciertos vínculos de parentesco. Nuestro análisis clarifica con precisión el tipo de vínculo genealógico implicado en los traspasos de tierras. Por otra parte, muestra que la política rapanui de la tierra es una mezcla de criterios locales y estatales, donde el parentesco sigue siendo determinante en la definición de la propiedad y su distribución. Esto es relevante en la medida que explica también los disensos en el seno de la sociedad rapanui. Las tierras son consideradas una propiedad en fragmentación en el seno del hua'ai, el que se refunda y combina con otros a lo largo del tiempo (Muñoz, 2014), lo cual, sin duda, repercute en las formas de adquisición. Encontramos aquí toda la complejidad de la política rapanui de la tierra: esta no es comunitaria en un sentido abstracto, sino restrictiva a cada hua'ai. El relativo control por parte de los hua'ai en cuanto a los procedimientos de distribución se ve afectado por la política del Estado, que instaló sus procedimientos cuando los rapanui ya habían definido los concensos necesarios para la gestión de las tierras. Esto explica también el relativo fracaso de la política chilena al insistir con la entrega de títulos que consagran la propiedad individual desvinculada del control que los hua'ai han ejercido históricamente sobre las tierras.

\section{Agradecimientos}

La redacción de este artículo fue apoyada y financiada por el European Union's Horizon 2020 Research and Innovation Programme a través de ERC Starting Grant № 803302 'Indigeneities in the 21st Century' coordinado por el profesor Philipp Schorch (LMU, Alemania).

Estoy en deuda con los colegas Andrea Seelenfreund, Rolf Foerster, Hans Gunderman y Philipp Schorch por sus comentarios a una versión previa de este artículo. Agradezco igualmente a Jimena Ramírez y Alex Icka por la valiosa ayuda entregada en la Oficina Provincial del Ministerio de Bienes Nacionales de Isla de Pascua, así como también a Francisco Torres por permitirme el estudio de los archivos conservados en el Museo Antropológico Padre Sebastián Englert. En fin, estoy igualmente en deuda con mis amigos rapanui, que siempre contestan a mis insistentes preguntas: Lenky y Hugo Atan Hito, Leonardo Pakarati, Moisés Hereveri Pakarari, María Haoa Pakomio, John Tuki Pakarati y Tamara Rapu Tuki. 


\section{Notas}

${ }^{1}$ Para una lista de los diferentes significados de la palabra kainga y sus variantes lingüísticas consultar: https://pollex.shh.mpg.de/ entry/kaaiga.a/. En todas ellas existe la asimilación de una tierra a un grupo de individuos emparentados.

${ }^{2}$ Para el análisis de las diferentes versiones de este mapa ver Foerster et al. (2014).

${ }^{3}$ Como lo son los títulos de dominio entregados a la Iglesias católica o la Iglesia mormona, así como al menos diez títulos otorgados a chilenos no rapanui. El caso más emblemático de estos corresponde al hotel Hangaroa que opuso a un gran grupo económico a una familia rapanui.

${ }^{4}$ Estas corresponden al fundo Vaitea $(27,69 \%$ de la superficie de la isla), las tierras de la Dirección Aeronáutica (1,75\%), las oficinas públicas $(0,40 \%)$, el borde costero e islotes (6\%), la Armada (cifras desconocidas) y aquellas del Parque Nacional (41,64\%) (MBN, 2011). Recordemos que hoy el Parque Nacional Rapa Nui es administrado por la comunidad indígena Ma'u Henua.

${ }^{5}$ Pacific Manuscripts Bureau, MS 531, The Routledge Collection.

${ }^{6}$ Biblioteca William Mulloy, Manuscritos de Sebastián Englert, DE 046-DE 050.

${ }^{7}$ Censo de 1886 (McCall, 1976); censo de 1916 (Biblioteca William Mulloy); censo de 1929 (Archivo Nacional, Intendencia de Valparaíso, vol. 919); censo de 1935 (Drapkin, 1935); censo de 1965 (Pacific Manuscripts Bureau, MS 532-536, METEI Census).

${ }^{8}$ https://www.kintip.net/.

${ }^{9} \mathrm{https}: / /$ aviz.fr/geneaquilts.

${ }^{10}$ Los registros de propiedades de los años 1921-1947 pueden ser consultados en el Archivo Nacional, Fondo Intendencia de Valparaíso, vol. 919. Copias de estos documentos se encuentran en la Oficina de Bienes Nacionales de Isla de Pascua y en 2014 fueron publicadas como anexo en Foerster et al. (2014). En cuanto a las cesiones de derechos, estas se encuentran digitalizadas y sistematizadas por el apellido del cesionario en la Biblioteca William
Mulloy, Museo Antropológico Sebastián Englert, Isla de Pascua. Nosotros tuvimos acceso a dichos documentos durante nuestra investigación de terreno en 2011.

${ }^{11}$ Según este documento, señalado como el número 8 del Consejo de Estado Rapanui (compuesto por Jean Batiste Dutrou-Bornier, los misioneros Gaspar Zumbohm e Hyppolite Roussel, más los rapanui Ludovico Manu, Huimpré, Husehai y Fabiano Ganka) este sector fue vendido por Nai, Ruka Puha, Manu a Rurem, Nune a Reka y Pohie Maio. Las tierras son Ilamadas: Hauiahua, Hangaroa, Vairanga, Punapoo y Rantapu Puna Poo (ver Vergara, 1939, anexo XIV). Hemos respetado la ortografía de los nombres tal como aparece en el documento citado.

${ }^{12}$ McCall (1976) precisa que los Hamea ya no tienen representantes en el censo de 1886 (p. 315).

${ }^{13}$ Ex. Intendencia de Valparaíso, vol. 919, f. 231.

${ }^{14}$ Ex. Intendencia de Valparaíso, vol. 919, f. 251.

${ }^{15}$ Cabe señalar que, en 2010, cuando estalló la "ola reivindicativa de tierras" (Zurob, 2011), las familias rapanui utilizaron los títulos provisorios y los croquis que los acompañan para reclamar al Estado la devolución de tierras.

${ }^{16}$ Entre estas competencias está la de analizar las necesidades de tierras de los rapanui (Ley 19.253, Art. 67, 69).

${ }^{17}$ Estos eran: a) los que sean hijos de padre o madre indígena, cualquiera sea la naturaleza de su filiación, inclusive la adoptiva; b) los descendientes de las etnias indígenas que habitan el territorio nacional, siempre que posean a lo menos un apellido indígena, y c) los que mantengan rasgos culturales de alguna etnia indígena, entendiéndose por tales la práctica de formas de vida, costumbres o religión de estas etnias de un modo habitual o cuyo cónyuge sea indígena. En estos casos, será necesario, además, que se autoidentifiquen como indígenas (Ley 19.253, Art. 2).

${ }^{18}$ El Mercurio de Valparaíso, 15 de noviembre de 2010.

${ }^{19}$ Radio Universidad Católica de Valparaíso, 6 de agosto de 2013. 


\section{Referencias bibliográficas}

Balandier, G. (1996). Anthropologie politique. París: PUF.

Bambridge, T. (2009). La terre dans l'archipel des Australes: Étude du pluralisme juridique et culturel en matière foncière. Pirae: Au vent des îles.

Barry, L., Bonte, P., D'Onofrio, S., Govoroff, N., Jamard, J.-L., Mathieu, N.-C., Porqueres i Gené, E., Wilgaux, J., Zempléni, A. \& Zonabend, F. (2000), Glossaire de la parenté, L'Homme (154-155), 721-732.

Bensa, A. (2006). La fin de l'exotisme: Essais d'anthropologie critique. Toulouse: Anacharsis.

BNC (Biblioteca de Congreso Nacional) (1998). Historia de le ley 19.587: Modifica los artículos 67 y 69 de la Ley 19.253 de protección, fomento y desarrollo de los pueblos indígenas, respecto a la constitución del dominio en la Isla de Pascua para los miembros de la comunidad Rapa Nui. Recuperado de www.bcn.cl/historiadelaley. Consulta: 9 de agosto de 2018.

CONADI (2011). Ley Indígena №19.253: Establece normas sobre protección, fomento y desarrollo de los indígenas, y crea la Corporación Nacional de Desarrollo Indígena. Temuco: Gobierno de Chile.

De Estella, B. (1921). Mis viajes a Pascua. Santiago: Imprenta Cervantes.

Delsing, R. (2009). Articulating Rapa Nui: Polynesian cultural politics in a Latin American Nation State. (Tesis inédita de doctorado). Santa Cruz: Universidad de California.

Drapkin, I. (1935). Contribución al estudio antropológico y demográfico de los pascuenses. Journal

de la Société des Américanistes de Paris, 27, 256-302.

Englert, S. (1948). La tierra de Hotu Matu'a: Historia, etnología y lengua de la Isla de Pascua. Padre las Casas: Imprenta San Francisco.

Fischer, R. S. (2005). Island at the end of the world: The turbulent history of Easter Island. Londres: Reaktion Books.

Firth, R. (1936). We, the Tikopia: A sociological study of kinship in primitive Polynesia. Londres: Allen and Unwin.

Foerster, R., Moreno Pakarati, C. \& Ramírez, J. (2014). Cartografía y conflicto en Rapa Nui. Isla de Pascua: Rapanui Press.

Godelier, M. (2009). Métamorphoses de la parenté. París: Flammarion Champs.

Hotus, A. \& Consejo de Jefes Rapanui (1988). Te Mau Hatu O Rapa Nui: los soberanos de Rapa Nui, pasado, presente y futuro. Santiago: Emisión.

(2007). Te Mau Hatu o Rapa Nui: los soberanos de
Rapanui. Sin datos de edición.

Hamberger, K., Houseman, M. \& Grange, C. (2009). La parenté radiographiée: un nouveau logiciel pour l'analyse des réseaux matrimoniaux. L'Homme (191), 107-138.

Gómez, R. (2004). Informe final sobre catastro de tenencia, dominio y transferencias de inmuebles en Isla de Pascua. Ministerio de Bienes Nacionales, Oficina Provincial de Isla de Pascua.

(2019). Rapanui y Chile. Recuperado de: https://www. wgtn.ac.nz/_data/assets/pdf_file/0003/1762707/Gomez.pdf

Loti, P. (2006 [1872]). L'île de Pâques: Journal d'un aspirant de La Flore. Joué-les-Tours: Christian Pirot.

McCall, G. (1976). Reaction to disaster: Continuity and change in Rapanui social organization. (Tesis inédita de doctorado). Canberra: Australian National University.

(1986). Las fundaciones de Rapanui. Isla de Pascua:

Museo R. P. Sebastián Englert.

Métraux, A. (1971 [1940]). Ethnology of Easter Island. Honolulu: Bishop Museum Press.

MBN (Ministerio de Bienes Nacionales) (2011). Minuta: situación de la tierra y el trabajo del Ministerio de Bienes Nacionales en Isla de Pascua. Oficina Provincial de Isla de Pascua.

Muñoz, D. (2017a). Diaspora Rapanui (1871-2015): L'île de Pâques, le Chili continental et la Polynésie française: une ethnographie historique de la mobilité dans une société transnationale. (Tesis inédita de doctorado). EHESS, Marsella.

(2017b). Memorias genealógicas de Rapa Nui: Conexiones pasadas, presentes y futuras. En Fajreldin, V. (Ed.), Historia, espacialidad y territorio en Rapanui. Santiago: Ocho Libros.

(2014). Kinship predicament in Rapa Nui (Easter Island): Autochthony, foreign and substantial identities. Rapa Nui Journal, 28(2), 25-34.

Porteous, D. (1981). The modernization of Easter Island. Western Geographical Series, 19. Victoria: University of Victoria.

Rochna, S. (1996). La propiedad de la tierra en Isla de Pascua. Santiago: CONADI.

Routledge, K. (1919). The mystery of Easter Island: The story of an expedition. Londres: Sifton, Praed \& Co Ltd.

Vergara, V. (1939). La Isla de Pascua: Dominación y dominio. Santiago: Publicaciones de la Academia Chilena de Historia.

Zurob, C. (2011). Familia, propiedad y herencia en Rapa Nui. Revista Anales de la Universidad de Chile, 7(2), 167-185. 


\section{Anexo}

Lista de nombre de "propietarios de parcelas", 1942

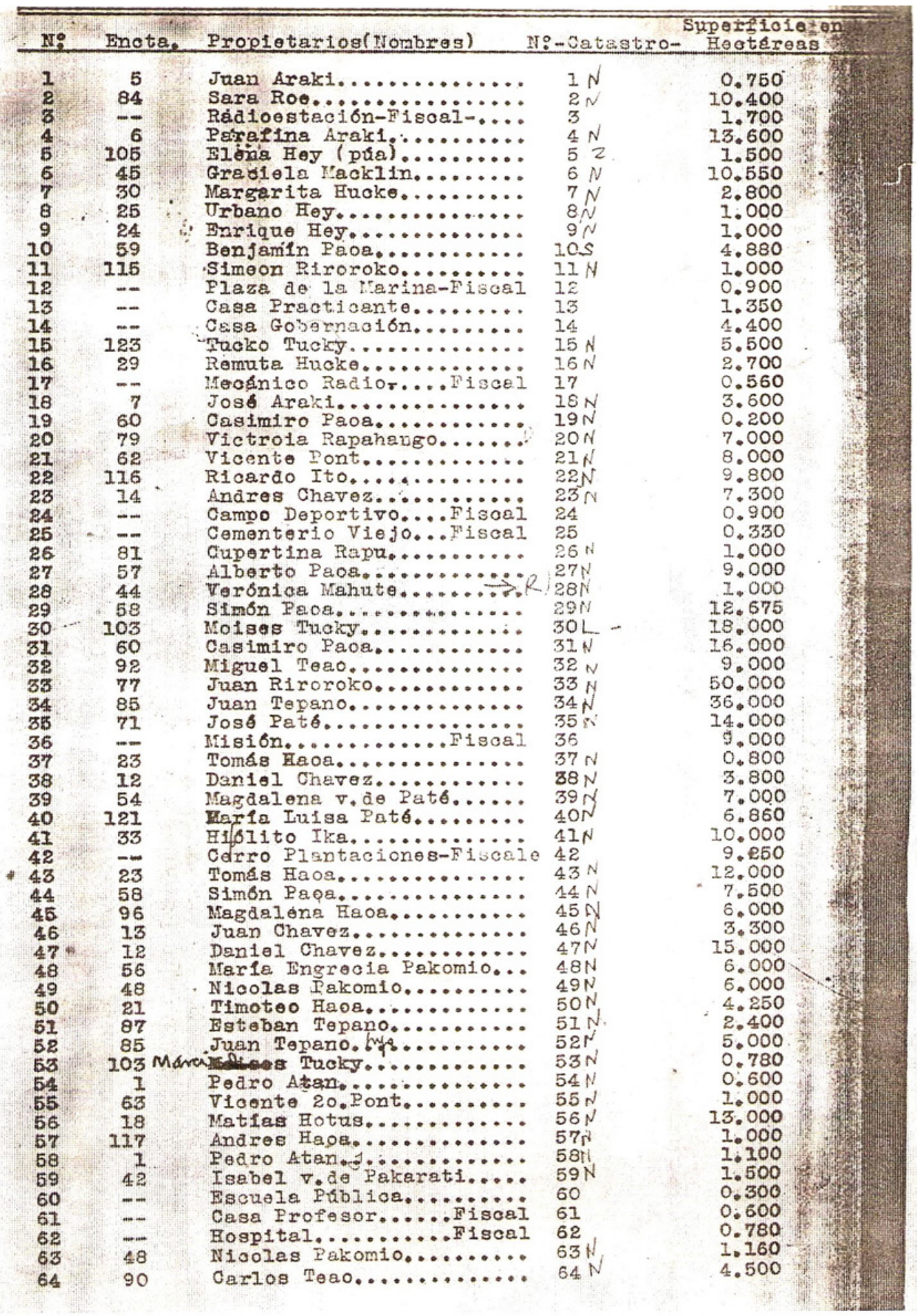




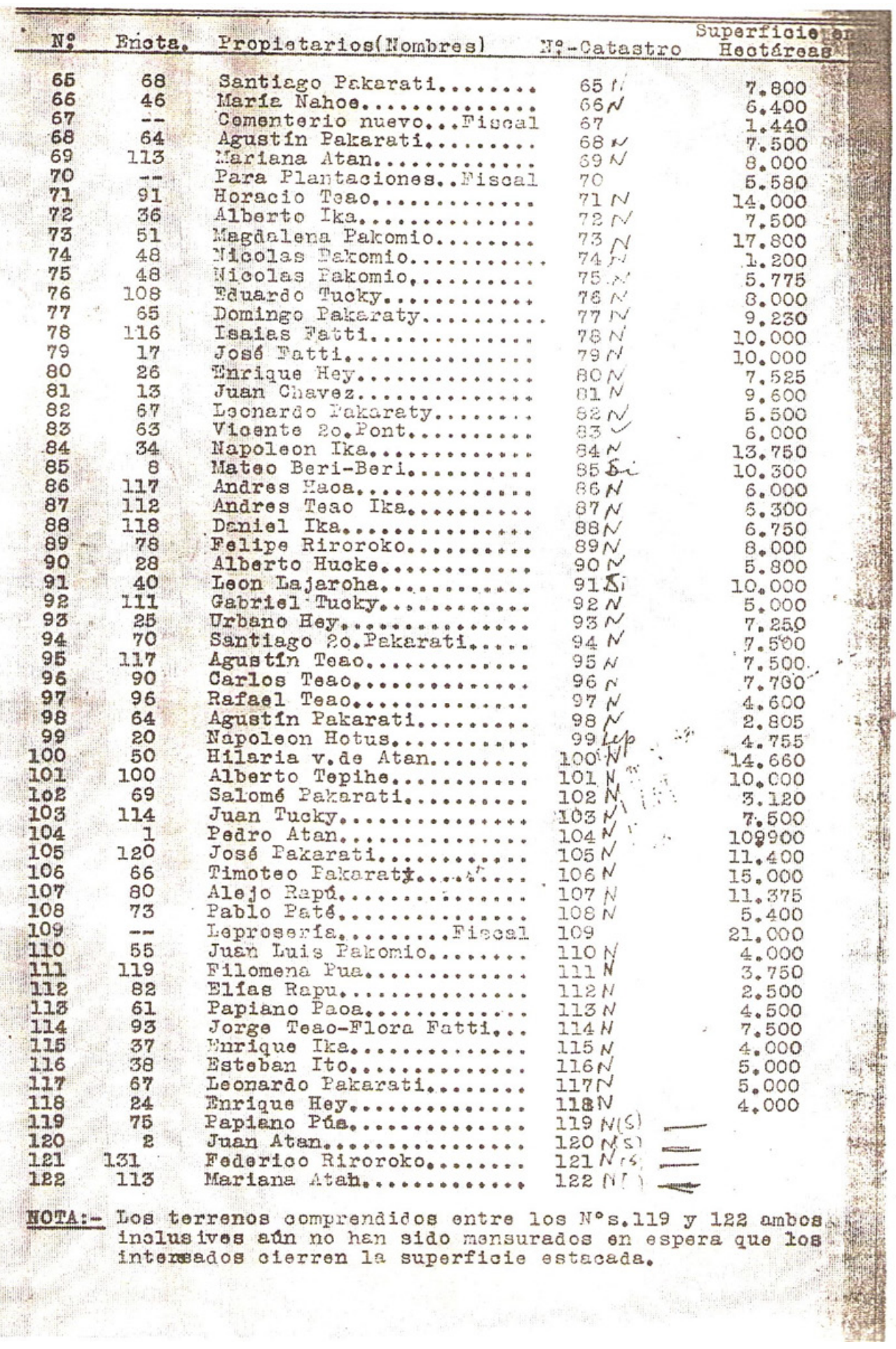

Fuente: Bienes Nacionales, Oficina Provincial Isla de Pascua. 